\title{
Determination of the Youngest Active Domain in Major Fault Zones Using Medical X-ray Computed Tomography-derived Density Estimations
}

akiyuki iwamori ( $\square$ iwamori.akiyuki@d5.kepco.co.jp )

School of Creative Science and Engineering, Waseda University https://orcid.org/0000-0001-83129720

\section{Hideo Takagi}

Faculty of Eucation and Integrated Arts and Sciences, Waseda University

\section{Nobutaka Asahi}

Dia ConsultantsCo. Ltd.

\section{Tatsuji Sugimori}

Dia Cnsultants Co. Ltd.

\section{Eiji Nakata}

Central Research Institute of Electric Power Industry

\section{Shintaro Nohara}

Central Research Institute of Electric Power Industry

\section{Keiichi Ueta}

Central Research Institute of Electric Power Industry

\section{Research Article}

Keywords: medical X-ray CT, CT number, beam hardening, bulk density, effective atomic number, rock/protolith density ratio, the youngest active domain of a fault zone

Posted Date: April 1st, 2021

DOl: https://doi.org/10.21203/rs.3.rs-342540/v1

License: (c) (i) This work is licensed under a Creative Commons Attribution 4.0 International License. Read Full License 


\section{Determination of the youngest active domain in major fault}

2 zones using medical X-ray computed tomography-derived

3 density estimations

$4 \quad$ Akiyuki Iwamori ${ }^{1,2}$

5 Corresponding author

6 Email: iwamori.akiyuki@d5.kepco.co.jp

7

$8 \quad$ Hideo Takagi ${ }^{3}$

$9 \quad$ Email: hideo@waseda.jp

10

11 Nobutaka Asahi ${ }^{4}$

12 Email: n.asahi@diaconsult.co.jp

14 Tatsuji Sugimori $^{4}$

15 Email: T.Sugimori@diaconsult.co.jp

16

$17 \quad$ Eiji Nakata $^{5}$

18 Email: nakata@criepi.denken.or.jp 
21 Email: nohara-s@criepi.denken.or.jp

23 Keiichi Ueta ${ }^{5}$

24 Email: ueta@criepi.denken.or.jp

25

26 (Institutional addresses)

$27{ }^{1}$ Kansai Electric Power Co. Inc., 3-6-16, Nakanosihma, Kita-ku, Osaka, 530-8270, Japan

282 School of Creative Science and Engineering, Waseda University, 1-6-1, Nishiwaseda,

29 Shinjuku-ku, Tokyo, 169-8050, Japan

303 Faculty of Education and Integrated Arts and Sciences, Waseda University, 1-6-1,

31 Nishiwaseda, Shinjuku-ku, Tokyo, 169-8050, Japan

$32{ }^{4}$ Dia Consultants Co. Ltd., 5-3, Toyotsu-cho, Suita-shi, Osaka, 564-0051, Japan

$33{ }^{5}$ Central Research Institute of Electric Power Industry, 1646 Abiko, Abiko-shi, Chiba, 270-

34 1194, Japan

35

36 Abstract

37 Determination of the youngest active domains in fault zones that are not overlain by Quaternary 
sedimentary cover are critical for evaluating recent fault activity, determining the current local stress field, and mitigating the impacts of future earthquakes. Considering the exhumation of a fault zone, the youngest active domain in a fault zone is supposed to correspond to the activity at the minimum fault depth of a buried fault, such that the most vulnerable area, which possesses the lowest rock/protolith density ratio, is assumed to be indicative of this recent fault activity. However, it is difficult to measure the density of fault rocks and map the rock/protolith density ratio across a given fault zone. Here we utilize medical X-ray computed tomography (CT), a non-destructive technique for observing and analyzing materials, to investigate the fault characteristics of several fault zones and their surrounding regions in Japan, and attempt to determine the youngest active domain of a given fault zone based on its CT numbers, which are a function of the density and effective atomic number of the fault rock and protolith. We first investigate the density, void ratio, and effective atomic number of active and inactive fault rocks, and their respective protoliths. We then calculate the CT numbers after reducing the beam-

51 hardening effects on the rock samples, and study the relationships among the CT number, density, and effective atomic number. We demonstrate that the density, effective atomic number, and CT number of the fault rock decrease as the youngest active zone is approached, such that

54 the region with the lowest CT number and rock/protolith density ratio defines the youngest 55 active domain of a given fault zone. 
Keywords

medical X-ray CT, CT number, beam hardening, bulk density, effective atomic number, rock/protolith density ratio, the youngest active domain of a fault zone

\section{Introduction}

Determination of the youngest active domain in fault zones that are not overlain by Quaternary cover are integral not only for evaluating fault activity and restoring the most recent stress field using slip data, but also for proposing local/regional earthquake disaster mitigation measures.

Various methods have been employed to potentially determine the youngest active domain in fault zones in bedrock (e.g., Mizoguchi and Ueta, 2012; Shigematsu et al., 2017; Tanaka et al., 2018). Considering the exhumation of a fault zone, this youngest active domain in a fault zone is supposed to correspond to the activity at the minimum fault depth of a buried fault, such that this most vulnerable area is assumed to be the area that possesses the lowest rock/protolith density ratio. Previous studies have focused on the density of the rocks around the fault zone (e.g., Morrow and Lockner, 2001; Takeuchi et al., 2005); however, a quantitative density-based classification of fault rocks has not been performed to date. Ikeda et al. (2001) performed geophysical well logging in the borehole through the Nojima Fault Zone, which was active 
74 during the 1995 Hyogo-ken Nanbu Earthquake, and reported that the non-fractured granite and

75 the fault zone densities were $2.6-2.7$ and $1.5-2.5 \mathrm{~g} / \mathrm{cm}^{3}$, respectively. However, it is difficult to

76 measure the density of fault rocks. Here we utilize medical X-ray computed tomography (CT)

77 in an attempt to determine the youngest active domain in a given fault zone based on its CT

78 numbers.

79 X-ray $\mathrm{CT}$ is a non-destructive technique that images the three-dimensional (3D) internal

80 structure of materials. The potential of X-ray CT in geoscience was recognized soon after its

81 development as a medical imaging technique in 1972 (Hounsfield, 1973), resulting in numerous

82 geoscience applications since the 1980s (e.g., Wellington and Vinegar, 1987; Raynaud et al.,

83 1989; Orsi et al., 1994; Boespflug et al., 1995; Verhelst et al., 1996; Geet et al., 2000; Ueta et

84 al., 2000). Hirono et al. (2008) used X-ray CT to analyze the fault rocks generated during the

851999 Chi-Chi Earthquake; however, they were unable to report on the relationship between the

86 CT number and fault rock density, owing to the beam hardening $(\mathrm{BH})$ effect. Aiyama et al.

87 (2017) recently observed the internal structure of a fault fracture zone using medical X-ray CT,

88 and reported that the CT image of the fault gouge zone was darker and less dense than that of

89 the surrounding cataclasite.

90 X-ray CT is generally conducted using either industrial- or medical-grade scanners. Industrial

91 scanners employ high-energy X-rays, and are used to examine dense rocks or minerals. Medical 
scanners can also be employed in a geoscience context to study low-density, unconsolidated

93 sediments (Nishizawa et al., 1995). Medical scanners are easier to operate than industrial

94 scanners, but the resulting CT images, which are obtained at lower X-ray intensities, include

95 artifacts, such as BH (Ketchman and Carlson, 2001). Nakano et al. (2000) observed and

96 analyzed the internal structures of lake sediment, basalt, and granite samples using a medical

97 scanner after accounting for X-ray attenuation and reducing the BH effect. However, the 98 applicability of their methodology is not straightforward because a priori knowledge of the X-

99 ray spectrum of the scanner is required. Ketchman and Hanna (2014) and Geet et al. (2000)

100 investigated the use of micro-CT in reducing the BH effects. Geet et al. (2000) estimated the

101 density and effective atomic number via the dual-energy method, which uses CT images

102 acquired at two different tube voltages; this approach is used to discriminate materials by

103 focusing on changes in the contrast of the $\mathrm{CT}$ images due to the X-ray energy differences of the

104 imaged materials.

105 Iwamori et al. (2020) investigated six different mineral samples with known densities and

106 effective atomic numbers using medical CT images, and defined the CT values for these

107 minerals, thereby providing an effective way to reduce the BH effect. Iwamori et al. (2020) also

108 presented a method for determining the density and effective atomic number via the dual-energy

109 method, and a method for estimating the density and effective atomic number using CT images 
taken with one tube voltage.

111 Here we present a method to determine the youngest active domain in major fault zones using

112 medical X-ray CT characteristics on the fault rock densities and effective atomic numbers. We

113 first investigate the density, void ratio, and effective atomic number of active and inactive fault

114 rocks, and their respective protoliths. We then calculate the CT numbers from CT images where

115 the BH effects have been reduced, and study the relationship among the CT number, density,

116 and effective atomic number. We reduce the effects of sample thickness variations and CT

117 image quality deterioration due to the X-ray energy reduction by adjusting the sample size and

118 imaging direction based on a $\sim 10 \mathrm{~cm} \mathrm{X-ray} \mathrm{transmission} \mathrm{thickness.}$

\section{Geological structural characteristics and rock structural} properties of each analyzed fault

122 We analyzed three faults, the Median Tectonic Line (MTL), and the Yamada and Tsuruga faults,

123 for our medical X-ray CT analysis. We chose the MTL since it is one of the longest onshore

124 faults in Japan, with both active and inactive fault outcrops; the protoliths of the fault rocks

125 consist mainly of Sanbagawa schists and Ryoke tonalites. We chose the Yamada Fault as an

126 example of an active fault in granite, and the Tsuruga Fault as an example of an active fault at

127 the geological boundary between metabasalt and granite. We focused on the fault rocks in the 
128 basement rock since the fault rock characteristics of the basement rock and basement rock-

129 sediment contact zone are thought to be different. The sample details are provided in Table 1,

130 with the geological outline of the study region and detailed geological maps of the investigated

131 faults shown in Figs 1 and 2, respectively. Here we define an "active fault" as a fault that has

132 been active since the late Pleistocene, and an "inactive fault" as a fault that has no recorded

133 activity since the late Pleistocene.

\subsection{MTL in the Ina area, Nagano Prefecture (Hiji outcrop; active fault)}

137 The MTL is the longest onshore fault and extends across the central part of southwestern Japan

138 for more than 1,000 km (e.g., Okada, 1992). The MTL is an approximately N-S-trending,

139 vertically dipping feature in the Ina area of Nagano Prefecture. Mylonitic rocks that originated

140 from Hiji tonalite are distributed within $\sim 1 \mathrm{~km}$ of the western side of the MTL in this area, with

141 increasing grain-size reduction and alteration closer to the MTL; however, fault breccia and

142 fault gouge are scarcely observed (Takagi, 1984). Conversely, the Sanbagawa schist on the

143 eastern side of the MTL is clayey and/or contains fractured lenticular bodies within a few meters

144 of the MTL, with minimal macroscopic fractures 10-20 m from the MTL (Takagi, 1984).

145 The Hiji outcrop $\left(35.80278^{\circ} \mathrm{N}, 138.08278^{\circ} \mathrm{E}\right)$ is located under a playground on the eastern bank 
146 of Lake Miwa, a dammed reservoir in the Ina area. The MTL, which forms the boundary

147 between the Hiji tonalite and the Sanbagawa schist (Fig. 3a), is clearly exposed, except in spring

148 when the reservoir is full. The fault is located $\sim 80 \mathrm{~cm}$ east of the MTL in this outcrop, where it

149 cuts a $<100$ ka terrace gravel deposit, and extends into the Sanbagawa schist without being

150 displaced by other foliations (Takagi et al., 2019). The strike and dip of the youngest fault plane

$151 \mathrm{Y}$ are N3E and 74W, respectively, and the observed striations on the slip plane possess a rake

152 of $20-30 \mathrm{~N}$ (Fig. 3a). The fault gouge zone along fault plane Y clearly shows a dextral sense of

153 shear (Fig. 3a, b). The observed displacement of $60 \mathrm{~cm}$ at the base of the terrace gravel deposit

154 due to fault plane $\mathrm{Y}$ equates to a real displacement velocity of $0.012-0.0118 \mathrm{~m} / \mathrm{ky}$ along this

155 fault, assuming the gravel layer was deposited 100,000 years ago (Takagi et al., 2019).

156 Sample HJ-8, which was derived from the Sanbagawa pelitic schist, was taken from the fault

157 zone that formed during the most recent fault activity at the Hiji outcrop. This fault rock sample

158 (Fig. 3b) can be divided into five zones based on their degree of cohesiveness and the

159 classification of Takagi and Kobayashi (1996). Zones HJ8-2-HJ8-4 are classified as fault

160 gouges, whereas zones HJ8-1 and HJ8-5 are cataclasites; the boundary between zones HJ8-2

161 and HJ8-3 is defined by the main fault plane Y, which cuts the terrace gravel deposit (Fig. 3b).

162 Protolith sample MZ-5 was collected from an outcrop $\left(35.79150^{\circ} \mathrm{N}, 138.08269^{\circ} \mathrm{E}\right)$ located $\sim 20$

$163 \mathrm{~m}$ east of the Mizoguchi outcrop (1.2 km south of the Hiji outcrop), which is where the MTL 
164 crops out; this sample was selected for comparison with the fault rocks.

165 Photomicrographs of the fault rocks are shown in Fig. 3c, d. The cataclasite zone (HJ8-1)

166 contains mainly $\leq 1$-mm-diameter quartz and albite fragments, with a dextral sense of slip

167 observed. Fine-grained clay minerals are distributed uniformly in the fault gouge zone (HJ8-3),

168 which is adjacent to fault plane Y, with a dextral sense of slip indicated. Sample MZ-5 consists

169 mainly of quartz, albite, phengite, calcite, and chlorite.

170

$<$ Figure 3

171

172

2.2 MTL in the Matsusaka area, Mie Prefecture (Awano-Tabiki outcrop; inactive

173 fault)

174 The MTL is an approximately E-W-trending feature in the Matsusaka area of Mie Prefecture

175 (Nishioka et al., 2010; Fig. 2b) that does not disrupt lower river terrace deposits, which means

176 that there has been no known activity during the late Quaternary (Okada, 1992). The Hatai

177 tonalite is distributed within $2 \mathrm{~km}$ of the northern side of the MTL in this area, and consists

178 mainly of plagioclase, hornblende, and chloritized biotite. The Hatai tonalite is affected by

179 mylonitization along the MTL, and contains foliations that are almost parallel to the MTL

180 (Takagi, 1985).

181 The Awano-Tabiki outcrop $\left(34.44294^{\circ} \mathrm{N}, 136.25292^{\circ} \mathrm{E}\right)$ is located in Awano and Tabiki, 
182 Matsusaka City, Mie Prefecture. This outcrop comprises Ryoke Hatai tonalite and Sanbagawa

183 schist (Fig. 3e). The Hatai tonalite consists of weathered, light-brown fault rocks with irregular

184 but well-developed cracks, and scarcely observed fault breccia and fault gouge in the Ryoke

185 Belt. Conversely, the Sanbagawa schist is partly clayey and shows a dextral sense of shear

186 within $2 \mathrm{~m}$ of the MTL, with minimal macroscopic fractures $10-20 \mathrm{~m}$ from the MTL.

187 Shigematsu et al. (2017) reported that four stages of deformation have been recorded in the

188 fault zone at this outcrop since the Paleocene, with the final stage consisting of Miocene-age

189 normal faulting. Here we investigated faults on the boundary between the Ryoke and

190 Sanbagawa belts, with a focus on one of the two faults that Shigematsu et al. (2017) evaluated

191 as possessing the youngest active domain.

192 The fault on the boundary between the Ryoke and Sanbagawa belts shows good continuity

193 throughout the outcrop and is not disrupted by other faults. The most recent fault plane strikes

194 N76E and dips $31 \mathrm{~N}$, with the striations on the slip plane possessing a rake of $88 \mathrm{NNW}$. The fault

195 gouge zone (1-3 cm wide) along this fault shows a normal sense of shear, which is consistent

196 with the observed features that Shigematsu et al. (2017) identified as the final stage of

197 deformation (Fig. 3e, f).

198 Sample AT was taken from the fault zone that formed during the most recent fault movement

199 at this outcrop (Fig. 3f). This fault rock sample can be divided into five zones, based on their 
degree of cohesiveness: AT- 2 and AT- 3 are fault gouges, and AT-1, AT-4, and AT-5 are 201 cataclasites. AT-1 and AT-2 correspond to the Sanbagawa Belt, and zones AT-3, AT-4, and AT-5 202 correspond to the Ryoke Belt, with the boundary between AT-2 and AT-3 representing the main 203 fault plane (Y) of the geological MTL boundary.

204 We collected four rock samples from the Ryoke Belt (ATR and HA samples) and two rock 205 samples from the Sanbagawa Belt (ATS samples) for analysis. Cataclasite samples ATR-2 and 206 ATR-3 were collected $\sim 5 \mathrm{~m}$ to the north of the MTL (Fig. 3e), mylonite sample ATR-4 was 207 collected $300 \mathrm{~m}$ to the north of the MTL (Fig. 2b), and protolith sample HA-1 (Fig. 7g) was 208 collected $13.5 \mathrm{~km}$ ENE of the outcrop (Fig. 2b) to provide a comparison of the fault rock and 209 protolith characteristics with different degrees of cohesiveness. Protolith samples ATS-1 (20 m 210 to the south of the MTL) and ATS-2 (550 m to the south of the MTL) were collected from the 211 Sanbagawa Belt (Figs 3c and 2b). ATS-2 is a solid pelitic schist with well-developed schistosity, 212 whereas ATS- 1 contains 2 -cm-diameter quartz crystals. The cataclasite samples from the Hatai 213 tonalite were analyzed using X-ray CT imaging (ATR-2) and density and X-ray fluorescence 214 (XRF) analyses (ATR-3).

215 Photomicrographs of the fault rocks are shown in Fig. 3g, h. The thin AT section can be divided 216 into three zones, AT-1, AT-2, and AT-4, with the youngest fault plane Y extending through the 217 section without being displaced by other foliations. Zone AT-1, which consists of a Sanbagawa 
218 cataclasite, mainly contains $\leq 0.2-\mathrm{mm}$-diameter albite fragments, and shows a reverse sense of

219 shear. Zone AT-4, which consists of a Ryoke cataclasite, contains $\leq 0.5$-mm-diameter

220 mylonitized quartz fragments that have been affected by cataclastic flow, and 0.2 -mm-wide

221 calcite veins that have been displaced by a reverse sense of Riedel shearing. Fine-grained clay

222 minerals are uniformly distributed throughout the fault gouge in zone AT-2, with a normal sense

223 of slip indicated.

224 ATS-2, which is a Sanbagawa schist protolith, consists mainly of fine quartz, albite, phengite,

225 and calcite crystals ( $\leq 0.2$-mm-diameter crystals), and ATS- 1 contains mainly $\leq 0.2-\mathrm{mm}$ -

226 diameter quartz, albite, phengite, and graphite fragments. ATS-2 contains less phengite than

227 ATS-1, and the schistosities of both samples are regulated by the arrangement of the quartz and

228 albite aggregates and/or phengite.

229 Samples HA-1 and ATR-4 consist mainly of quartz, plagioclase, hornblende, and chlorite. HA-

2301 contains $\leq 2$-mm-diameter plagioclase and amphibole crystals and $\leq 0.5$-mm-diameter quartz

231 and chlorite crystals. Conversely, the mylonite ATR-4 sample contains $\leq 1$-mm-diameter

232 plagioclase and hornblende crystals, and voids that are filled with recrystallized quartz

233 aggregates. The cataclasite ATR-3 sample consists mainly of $\leq 0.2$-mm-diameter plagioclase,

234 quartz, and chlorite crystals and mylonitized quartz fragments that have been affected by

235 cataclastic flow. 


\subsection{Tsuruga Fault (Oritodani outcrop; active fault)}

238 The Tsuruga Fault is a $\sim 25-\mathrm{km}$-long, NE-SW-trending, right-lateral strike-slip fault in the

239 central Fukui Prefecture (National Institute of Advanced Industrial Science and Technology,

240 2016). Koujaku granite (Upper Cretaceous) and metabasalt (Middle-Upper Jurassic

241 accretionary complex) from the Mino-Tanba Belt occur around this fault (Fig. 2c). Kurimoto

242 et al. (1999) performed a trench excavation in the Ikenotani area and reported that the southern

243 part of the Tsuruga Fault was active between the latter half of the twelfth and end of the

244 fourteenth centuries, with a vertical displacement of 1.5-2 $\mathrm{m}$ and average vertical displacement

245 velocity of $0.5-0.6 \mathrm{~m} / 10^{3}$ years.

246 The Oritodani outcrop $\left(35.53750^{\circ} \mathrm{N}, 136.01906^{\circ} \mathrm{E}\right)$, which is located $1.7 \mathrm{~km}$ southwest of the

247 Ikenotani area, contains exposures of Koujaku granite and metabasalt, with a 10-20-cm-wide

248 fault gouge distributed along the geological boundary (Fig. 4a). The boundary fault between

249 the granite and metabasalt is continuous throughout the outcrop and cuts the terrace gravel

250 deposit. The strike and dip of the most recent fault plane are N49E and 78W, respectively, with

251 the striations on the slip plane possessing a rake of $15 \mathrm{~N}$. A very soft fault gouge (T-3-3 zone) is

252 developed in the metabasalt along its boundary with the granite fault gouge (T-3-2 zone) and

253 shows a dextral sense of shear (Fig. 4b, e). 
254 Sample T-3 was taken from the fault zone that formed during the most recent fault activity at 255 the Oritodani outcrop. This fault rock sample (Fig. 4b) can be divided into four zones based on 256 their degree of cohesiveness: T-3-1, T-3-2, and T-3-3 are fault gouges, and T-3-4 is a cataclasite.

257 T-3-1 and T-3-2 correspond to the Koujaku granite, and T-3-3 and T-3-4 correspond to the 258 metabasalt, with the main fault plane (Y) of the Tsuruga Fault extending through T-3-3. The 259 brown (T-3-1) and white (T-3-2) fault gouge zones are slightly harder than the T-3-3 zone, with 260 the P foliations in T-3-2 that have developed near the boundary with T-3-1 exhibiting a dextral 261 sense of slip (Fig. 4b), which indicates that the zone up to $10 \mathrm{~cm}$ from the main fault plane was 262 possibly affected by the most recent fault activity.

263 We collected cataclasite sample C-2 and protolith sample K-1 from the Koujaku granite at the 264 Oritodani outcrop to compare the degrees of cohesiveness in the samples. We also collected 265 cataclasite sample C-1 and protolith sample T-5 from the metabasalt of the Mino-Tanba Belt.

266 Photomicrographs of the fault rocks are shown in Fig. 4c, d, and e. The youngest fault plane Y

267 extends through T-3-3 without being displaced by other foliations. Fine-grained clay minerals 268 are distributed uniformly throughout fault gouge T-3-3, and developed P foliations with a

269 dextral sense of slip are present. Conversely, fault gouge T-3-2 mainly contains $\leq 0.2-\mathrm{mm}$ 270 diameter quartz, K-feldspar, and plagioclase fragments and no clear fault plane (Fig. 4c, d).

271 Therefore, the youngest activity of this fault is thought to have only been recorded in the most 
272 vulnerable fault gouge (T-3-3).

273 Protolith sample K-1 mainly consists of $\leq 3$-mm-diameter quartz, plagioclase, K-feldspar and

274 biotite crystals. Cataclasite sample C-2 mainly consists of $\leq 0.3$-mm-diameter quartz,

275 plagioclase, K-feldspar, and biotite crystals. Conversely, sample T-5 mainly consists of $\leq 0.1$ -

276 mm-diameter hornblende and clinopyroxene crystals, whereas sample C-1 mainly consists of

277 hornblende, chlorite, and plagioclase fragments, and fewer hornblende crystals than in sample 278 T-5.

\subsection{Yamada Fault (Musyu outcrop; active fault)}

282 The Yamada Fault Zone is an ENE-WSW-trending dextral fault that forms the $\sim 33-\mathrm{km}$-long

283 Yamada Fault Zone at the base of the Tango Peninsula, northern Kyoto Prefecture (Earthquake

284 Research Committee, 2004). This fault zone is composed of the Yasukeyama, Yamada, and

285 Koryuji faults; we hereafter identify the Yamada Fault Zone as the Yamada Fault. Miyazu

286 granite (Upper Cretaceous-Paleogene) is present around the Yamada Fault (Fig. 2d).

287 The Mushu outcrop $\left(35.51722^{\circ} \mathrm{N}, 136.00797^{\circ} \mathrm{E}\right)$ contains a cataclasite zone of Miyazu granite, 288 and a fault with a 1-2-cm-wide fault gouge that is continuous throughout the outcrop (Fig. 4f).

289 The strike and dip of the youngest fault plane are N55E and 62W, respectively, with striations 
on the slip plane possessing a rake of 20S. The fault gouge zone is very soft, and shows a dextral

291 sense of shear. Aiyama et al. (2017) investigated the activity of this fault in the Mushu outcrop,

292 and reported that the main fault plane, which has been active during the Quaternary, contains a

293 fault gouge zone. Aiyama et al. (2017) also characterized this fault gouge zone as a layered

294 structure with ten fault gouge layers that are indicative of repetitive activity after smectite

295 crystallization. Iwamori et al. (2015) studied the activity of the Yamada Fault over the last

$296 \sim 200,000$ years based on the faults that cut the sedimentary layer above the Mushu outcrop, and

297 reported that the youngest fault activity occurred between 2,000 and 200 years B.P.

298 Sample YDA was taken from the fault zone that formed during the most recent fault activity at

299 the Mushu outcrop (Fig. 4g). This fault rock sample can be divided into four zones based on

300 their degree of cohesiveness: YDA-1 and YDA-2 are fault breccias, YDA-3 is a fault gouge,

301 and YDA-4 is a cataclasite. The boundary between YDA-2 and YDA-3 represents the main

302 fault plane $\mathrm{Y}$, and the fault breccias are dark brown due to iron oxide deposition. We collected

303 a Miyazu granite protolith sample (YK-1) at Karakawa, $\sim 6 \mathrm{~km}$ WSW of the Mushu outcrop,

304 for comparison with the fault rocks.

305 Photomicrographs of the fault rocks are shown in Fig. 4h, i. The youngest fault plane Y extends

306 along the boundary between the YDA-2 and YDA-3 fault gouge zones without being displaced

307 by other foliations. YDA-3 consists of a fine-grained clay mineral matrix that contains a mainly 
uniform distribution of $\leq 0.2$-mm-diameter quartz, K-feldspar, and plagioclase fragments, and possesses a $\mathrm{P}$ foliation that indicates a dextral sense of slip. Conversely, fault breccia YDA-2 mainly consists of $\leq 0.3$-mm-diameter quartz, K-feldspar, plagioclase, and biotite fragments in a matrix of brown clay minerals. Cataclasite YDA-4 mainly consists of $\leq 0.2$-mm-diameter

312 quartz, K-feldspar, plagioclase, and biotite fragments in a clay mineral matrix. Conversely, protolith sample YK-1 is mainly composed of quartz, plagioclase, K-feldspar, and biotite $(\leq 5$ -

314 mm-diameter crystals).

\section{Density, porosity, and effective atomic number}

\section{$317 \quad 3.1$ Measurement method}

318 Different methods were employed to obtain density measurements for the protolith and fault

319 rock samples since the fault rock samples generally contained many voids. The density analysis

320 for the protolith samples was performed according to the standard Japanese test method for

321 determining the bulk density of rocks (JGS2132-2009; The Japanese Geotechnical Society,

322 2017). The densities of the fault rock samples were determined via mercury intrusion

323 porosimetry (AutoPore IV 9500, Version 2.02; Micromeritics; Norcross, Georgia, USA) at the

324 Central Research Institute of Electric Power Industry (CRIEPI; Abiko-shi, Chiba, Japan); this

325 analysis also allowed an examination of the microcracks and pores within each sample. 
326 The effective atomic number, $\mathrm{Z}_{\mathrm{e}}$, of a compound consisting of multiple types of atoms is defined as:

328

$Z_{\mathrm{e}}=\left(\Sigma f_{\mathrm{i}} Z_{\mathrm{i}}^{3.8}\right)^{1 / 3.8}$

329 where fi is the fraction of electrons on the ith atomic number species. For example, the effective

330 atomic number of a crystal composed of one silicon atom $(Z=14)$ and two oxygen atoms $(Z=$

$3318)$ is $\left(14 / 30 \times 14^{3.8}+16 / 30 \times 8^{3.8}\right)^{1 / 3.8}=11.85$. Here we calculated the effective atomic number,

$332 Z_{\text {et, }}$ of each sample based on the contents of the main components $\left(\mathrm{SiO}_{2}, \mathrm{TiO}_{2}, \mathrm{Al}_{2} \mathrm{O}_{3}, \mathrm{Fe}_{2} \mathrm{O}_{3}\right.$,

$333 \mathrm{MnO}, \mathrm{MgO}, \mathrm{CaO}, \mathrm{Na}_{2} \mathrm{O}, \mathrm{K}_{2} \mathrm{O}$, and $\mathrm{P}_{2} \mathrm{O}_{5}$ ), which were measured via XRF analysis. Fused glass

334 bead samples underwent XRF analysis using a spectrometer at CRIEPI (XRF-1500, Rh X-ray

335 tube; Shimadzu Co., Ltd.; Nakagyo-ku, Kyoto, Japan) to obtain the $Z_{\text {et }}$ values.

$337 \quad 3.2$ Measurement results

338 The density, $\rho_{\mathrm{t}}$, porosity, $\phi$, and $Z_{\mathrm{et}}$ measurement results are shown in Table 2 and Fig. 5, and

339 Table 3 contains the XRF analysis results, which were used to calculate $Z_{\text {et }}$.

340 There is a decrease in $\rho_{\mathrm{t}}$ as the youngest fault plane $\mathrm{Y}$ of every analyzed fault is approached

341 (Fig. 5a). There is an $\sim 24 \%$ increase in $\phi$ as $\rho_{\mathrm{t}}$ decreases by $1 \mathrm{~g} / \mathrm{cm}^{3}$, regardless of rock type

342 (fault rock or protolith; Fig. $5 \mathrm{~b}$ ). The mean $\phi$ values are $1.5 \%$ (standard deviation $(\mathrm{SD})=1.0 \%$ )

343 for the protolith, $12.6 \%(\mathrm{SD}=6.9 \%)$ for the cataclasite, $12.0 \%(\mathrm{SD}=4.8 \%)$ for the fault gouge 
344 along the inactive faults, $17.4 \%(\mathrm{SD}=4.6 \%)$ for the fault gouge along the active faults, and

$34532.2 \%$ (no SD calculated since there were only two samples) for the fault breccia (Table 2).

346 However, every rock type yielded a positive correlation between $\rho_{\mathrm{t}}$ and $Z_{\text {et }}$ (Fig. 5c), even

347 though the $\rho_{\mathrm{t}}$ and $Z_{\mathrm{et}}$ are expected to vary among different rock types. Fault breccia YDA-1 and

348 YDA-2 of the Yamada Fault both exhibit maximum $\rho_{\mathrm{t}}$ decreases of $\sim 40 \%$, whereas the $Z_{\text {et }}$ values

349 are almost the same as that for protolith $\mathrm{YK}-1$, which means that the relationship between $\rho_{\mathrm{t}}$

350 and $Z_{\text {et }}$ for the fault breccias is quite different from those of the other samples. This is because

351 YDA-1 and YDA-2 have been strongly affected by weathering, as evidenced by their dark-

352 brown color at outcrop and an $\mathrm{Fe}_{2} \mathrm{O}_{3}$ content of $4.28 \mathrm{wt} \%$, which is much higher than those of

353 the fault gouge, cataclasite, and protolith samples (Table 3). Therefore, the fault breccia samples

354 were excluded from the subsequent study of the $\rho_{\mathrm{t}}-Z_{\text {et }}$ relationships among the collected rock 355 samples. number, density, and effective atomic number

We conducted X-ray CT image analysis on the fault rock and protolith samples to determine 
$362 \rho_{\mathrm{t}}$ and $Z_{\mathrm{et}}$. We also attempted to quantitatively evaluate the characteristics of the fault rocks

363 using CT values. We analyzed 28 samples, excluding the fault breccia samples (YDA-1 and

364 YDA-2) because of their heterogeneity relative to the other samples.

\subsection{X-ray attenuation principle}

367 CT imaging captures the 3D X-ray attenuation distribution in a sample (e.g., Nakano et al., 368 2000; Tsuchiyama et al., 2000; Ketchman and Carlson, 2001). The basic equation for the 369 attenuation of a monoenergetic beam through a homogeneous material is given by Beer's Law:

$370 \quad I=I_{0} \exp (-\mu S)$,

372 where $I_{0}$ is the initial intensity of the incident X-ray beam, $I$ is its emergent intensity, $S$ is the 373 sample thickness, and $\mu$ is the linear X-ray attenuation coefficient (LAC) of the sample. The 374 LAC depends on both bulk density, $\rho$, and the atomic number, $Z$ (Wellington and Vinegar, 375 1987):

$376 \mu=\rho\left(\mathrm{a}+\mathrm{b} Z^{3.8} / E^{3.2}\right)$,

377 where $E$ is the $\mathrm{X}$-ray energy $(\mathrm{keV})$, a is a nearly energy-independent coefficient this is termed 378 the Klein-Nishina coefficient, and b is a constant. Equation (3) is applicable for monochromatic 379 X-rays, such as those from a synchrotron radiation facility. However, this equation does not 
hold for most commercial X-ray CT scanners, which use polychromatic X-ray beams, because

$381 \mu$ depends on the X-ray energy (e.g., Nakano et al., 2000; Tsuchiyama et al., 2000). The

382 photoelectric absorption of a compound consisting of multiple types of atoms is proportional to

383 the effective atomic number calculated via equation (1) (Wellington and Vinegar, 1987).

384 The $\mathrm{CT}$ number, $N_{\mathrm{CT}}$, which determines the contrast of a $\mathrm{CT}$ image, is defined as:

$385 N_{\mathrm{CT}}=1000 \times\left(\mu-\mu_{\mathrm{w}}\right) / \mu_{\mathrm{w}}$,

386 where $\mu_{\mathrm{w}}$ is the X-ray attenuation coefficient of pure water. A polychromatic X-ray CT scanner

387 will allow $\mu$ to vary depending on the X-ray energy (effective energy), as described above. The

388 influence of the variations in $\mu$ with the energy differences in an X-ray energy distribution is

389 reduced by calculating $N_{\mathrm{CT}}$, which is standardized using the $\mu$ ratio in equation (4). Substitution

390 of equation (3) into equation (4) therefore highlights the dependence of $N_{\mathrm{CT}}$ on $\rho$ and $Z_{\mathrm{e}}$ when

391 the tube voltage and X-ray effective energy of a medical scanner are held constant.

\section{$393 \quad 4.2$ CT image analysis methods}

394 A CT image is essentially a bitmap of each pixel's CT number; however, it also contains various

395 artifacts due to the X-ray photography and image reconstruction. Therefore, the effects of these

396 artifacts, especially $\mathrm{BH}$, must be eliminated or reduced to ensure the accuracy of the CT

397 numbers and therefore provide an accurate quantitative analysis. 

numbers along the edges of a sample are greater than those in the center. This occurs because the lower-energy X-rays are absorbed more readily than the higher-energy ones when

401 polychromatic X-rays pass through a sample near its center, where the transmission thickness 402 is large.

403 Geet et al. (2000) estimated the density, $\rho$, and effective atomic number, $Z_{\mathrm{e}}$, via the dual-energy 404 method using a micro X-ray CT scanner. The $\mu_{\mathrm{E}}$ coefficient, which is the effective LAC 405 corresponding to the effective energy of the X-rays, is derived from Eq. (3) as:

$406 \quad \mu_{\mathrm{E}} / \rho=\mathrm{A}(\mathrm{E})+\mathrm{B}(\mathrm{E}) Z_{\mathrm{e}}^{3.8}$

407 where A and B are constants depending E. The relationships among $\rho, Z_{\mathrm{e}}$, and $\mu$ are expressed 408 as follows, using the A and B values calculated by approximating the relationship between $\mu \mathrm{E} / \rho$ 409 and $Z_{\mathrm{e}}^{3.8}$ values at two different tube voltages:

$410 \rho=\left(\mathrm{B}_{\mathrm{h}} \mu_{E 1}-\mathrm{B}_{1} \mu_{E \mathrm{~h}}\right) /\left(\mathrm{B}_{\mathrm{h}} \mathrm{A}_{1}-\mathrm{B}_{1} \mathrm{~A}_{\mathrm{h}}\right)$

411 and

$412 \quad Z_{\mathrm{e}}=\left[\left(\mathrm{A}_{1} \mu_{E \mathrm{~h}}-\mathrm{A}_{\mathrm{h}} \mu_{E 1}\right) /\left(\mathrm{B}_{\mathrm{h}} \mu_{E 1}-\mathrm{B}_{1} \mu_{E \mathrm{~h}}\right)\right]^{\wedge}(1 / 3.8)$

413 where the $\mathrm{h}$ and 1 subscripts refer to the values derived from the high- and low-energy scans, 414 respectively.

415 Iwamori et al. (2020) used the dual-energy method (tube voltages: 140 and $100 \mathrm{kV}$ ) to analyze 
416 the medical CT images of six different minerals with known densities and effective atomic

417 numbers (quartz, calcite, fluorite, rhodochrosite, cryptomelane, and hematite). They found that

418 the modal CT number, $N_{\mathrm{CTM}}$, which is calculated from the two-dimensional (2D) CT image

419 whose peripheral $\mathrm{CT}$ values are excluded due to significant $\mathrm{BH}$, could be used to estimate the

$420 \rho$ and $Z_{\mathrm{e}}$ values of the mineral samples. Iwamori et al. (2020) also reported that the recorded

421 CT values for a single tube voltage $(140 \mathrm{kV})$ can be used to estimate $\rho$ and $Z_{\mathrm{e}}$ for the mineral

422 samples since these parameters possess a positive correlation.

423 We have already highlighted the positive correlation between $\rho$ and $Z_{\mathrm{e}}$ for each analyzed fault

424 and rock type in this study (Fig. 5c). Therefore, we investigated the relationship among $N_{\mathrm{CT}}, \rho$,

425 and $Z_{\mathrm{e}}$ using the recorded $\mathrm{CT}$ images taken for a single tube voltage $(140 \mathrm{kV})$.

426 We used a third-generation medical X-ray scanner (Aquilion Precision TSX-304A 160-row

427 multi-slice CT; Canon Medical Systems Co., Ltd.; Otawara, Tochigi, Japan) at CRIEPI. The

428 scanner has a $0.25-\mathrm{mm}$ slice thickness and $0.098-0.313-\mathrm{mm}$ pixel size. The X-ray tube has a W

429 target and a $0.4 \mathrm{~mm} \times 0.5 \mathrm{~mm}$ focal size. Three-dimensional CT images were acquired using a

430 single tube voltage $(140 \mathrm{kV})$ and a $300-\mathrm{mAs}$ tube current-time product. AIDR 3D (Canon

431 Medical Systems) was used for iterative approximation reconstruction (hybrid iterative

432 reconstruction method), with the FC30 reconstruction function employed. A CT image (1,024

$433 \times 1,024$ pixels) of an arbitrary $2 \mathrm{D}$ cross section near the center of the sample was extracted from 
434 the 3D CT image. The effective energy of $140 \mathrm{kV}$ was set to $64.1 \mathrm{keV}$ based on Hubbell's

435 (1982) measurement results for fixed irradiation using an aluminum plate.

436

437

\subsection{Results}

438 Table 4 shows the X-ray CT image, density, and XRF analysis results. $N_{\mathrm{CTM}}$ was obtained from

439 the central part of each 2D CT image (within the white dotted perimeters in Fig. 6). The

440 periphery of each CT image, where $\mathrm{BH}$ is significant and determined relative to the median $\mathrm{CT}$

441 value calculated for the entire arbitrary cross-sectional line (along the white dash-dotted line)

442 using the method outlined in Iwamori et al. (2020), was excluded.

\section{$445 \quad$ 4.3.1 The MTL at the Hiji outcrop}

446 The CT images for sample HJ-8, which is from the fault fracture zone in the Sanbagawa Belt,

447 is dark at the fault gouge zones (HJ8-2, HJ8-3, and HJ8-4; Fig. 6a). The $N_{\text {CTM values are in the }}$

448 994-1109 range across the fault gouge, with the smallest value obtained within zone HJ8-3,

449 which is in contact with the main fault plane Y. The cataclasite zones (HJ8-1 and HJ8-5), which

450 are outside the fault gouge zones, appear brighter than the fault gouge, with $N_{\text {CTM values in the }}$

451 1281-1333 range. 
452 The CT images for sample MZ-5, a pelitic schist protolith in the Sanbagawa Belt, exhibits a 453 striped pattern corresponding to planar schistosity (Fig. 6b) and possesses a $N_{\text {CTM value of } 2056 .}$

454 A narrow band ( $\leq 1 \mathrm{~mm}$ wide) that is brighter than the rest of the image is inferred to be a 455 phengite vein, which has a greater effective atomic number than either quartz or albite.

456 Example histograms of the CT values in each of the sampled zones are shown in Fig. 6c-e. 457 Approximately 40,000-130,000 pixels are analyzed in each region, with the $N_{\text {CTM values }}$ 458 generally following a normal distribution and possessing a standard deviation of 112-312 459 (Table 4). There may either be an increase in the frequency to values lower than $N_{\mathrm{CTM}}$, or a 460 small side peak that is lower than $N_{\text {CTM }}$ if the sample contains many cracks; however, $N_{\text {CTM }}$ 461 corresponds to the CT value of the matrix, with the influence of cracks excluded.

462 Figure $6 \mathrm{f}$ and g show the CT value distributions along the white dash-dotted lines in the CT 463 image. We note that the $N_{\text {CTMedian }}$ values (HJ-8: 991-1278, MZ-5: 2088) are almost consistent

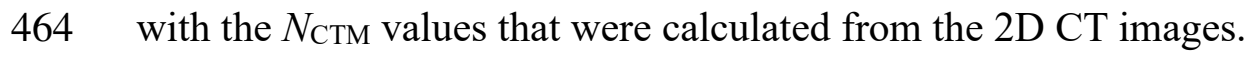

465 The $N_{\mathrm{CTM}}-\rho_{\mathrm{t}}$ relationship for Sanbagawa pelitic schist possesses a high positive correlation $\left(\rho_{\mathrm{t}}\right.$ $466=9.54 \times 10^{-4} N_{\mathrm{CTM}}+0.76, \gamma=0.958$; Fig. 10a). The calculated density from this equation, $\rho_{\mathrm{c}}$, 467 is consistent with the real value, $\rho_{\mathrm{t}}$, and possesses an error of $<9.5 \%$ (Table 4 ).

468 The $N_{\mathrm{CTM}}-Z_{\text {et }}$ relationship $\left(Z_{\text {et }}=2.67 \times 10^{-4} N_{\text {СTM }}+11.8\right)$ can be derived from the 469 abovementioned $N_{\mathrm{CTM}}-\rho_{\mathrm{t}}$ relationship; the $\rho_{\mathrm{t}}-Z_{\mathrm{et}}$ relationship is shown in Fig. $5 \mathrm{c}\left(Z_{\mathrm{et}}=0.28 \rho_{\mathrm{t}}+\right.$ 
$47011.6, \gamma=0.847)$. The effective atomic number calculated from this equation, $Z_{\mathrm{ec}}$, is consistent 471 with the real value, $Z_{\mathrm{et}}$, and possesses an error of $<1.4 \%$ (Table 4 ).

\subsubsection{The MTL at the Awano-Tabiki outcrop}

475 The imaging results for samples AT, HA-1, and ATS-2 (Fig. 7a-c) are representative of the 476 seven samples (AT, ATR-2, ATR-3, ATR-4, ATS-1, ATS-2, and HA-1) collected from the

477 Awano-Tabiki outcrop.

478 The CT image for sample AT, which was taken from rocks in the fault fracture zone that formed 479 during the most recent fault activity, appears dark in the fault gouge (AT-2 and AT-3) 480 surrounding the main fault plane Y (Fig. 7a), with $N_{\text {CTM }}$ values in the 1209-1665 range. The

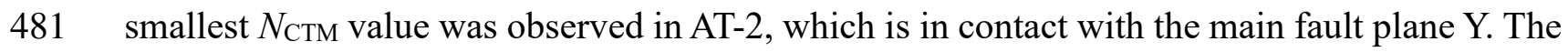
482 cataclasite samples (AT-1, AT-4, and AT-5), which are outside of the fault gouge zone, produce

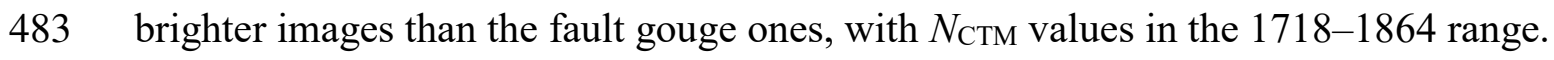

484 Sample HA-1, a Hatai tonalite protolith from the Ryoke Belt, possesses both dark-gray and

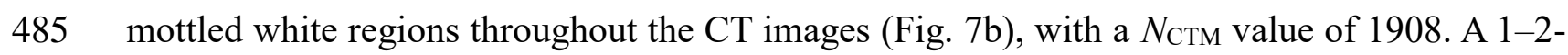
mm-thick band that appears brighter than the rest of the image is inferred to be hornblende and chlorite, both of which have larger effective atomic numbers than quartz and plagioclase. 
Sample ATS-2, a pelitic schist protolith from the Sanbagawa Belt, possesses striped patterns

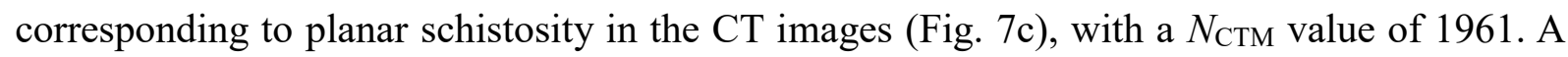
narrow band (at most $\sim 1 \mathrm{~mm}$ wide) that appears brighter than the rest of the image is inferred to be a thin layer containing phengite and calcite, both of which have larger effective atomic

492 numbers than quartz.

493 Example CT value histograms for each zone are shown in Fig. 7d-h. Approximately 12,000494200,000 pixels are analyzed in each zone, with the $N_{\text {CTM values generally following a normal }}$ 495 distribution and possessing a standard deviation of 90-210 (Table 4). There may be a slight 496 increase in the frequency to values higher than $N_{\text {СTM }}$ due to the influence of minerals with a 497 large effective atomic number in some instances; however, $N_{\text {CTM }}$ corresponds to the CT value 498 of the matrix, with the influence of these minerals excluded.

499 Figure 7i-k shows the CT value distributions along the white dash-dotted line in the CT image.

500 We note that the $N_{\text {CTMedian }}$ values (AT: 1386-1801, HA-1: 1965, ATS-2: 1953) are almost

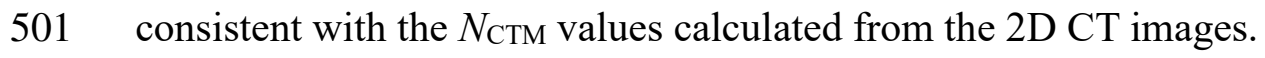

502 The $N_{\mathrm{CTM}}-\rho_{\mathrm{t}}$ relationships for the Sanbagawa pelitic schist and Ryoke tonalite possess high 503 positive correlations (pelitic schist: $\rho_{\mathrm{t}}=1.08 \times 10^{-3} N_{\mathrm{CTM}}+0.56, \gamma=0.857$; tonalite: $\rho_{\mathrm{t}}=1.19$ $504 \times 10^{-3} N_{\mathrm{CTM}}+0.40, \gamma=0.813$; Fig. $\left.10 \mathrm{~b}, \mathrm{c}\right)$. The $\rho_{\mathrm{c}}$ values are consistent with the $\rho_{\mathrm{t}}$ values, and 505 possess errors of $<10.7 \%$ (Table 4 ). 
506 The $N_{\text {СтM }}-Z_{\text {et }}$ relationships (pelitic schist: $Z_{\text {et }}=1.57 \times 10^{-3} N_{\text {СтM }}+9.47$; tonalite: $Z_{\text {et }}=3.31 \times$

$\left.50710^{-3} N_{\text {СтM }}+5.87\right)$ can be derived from the abovementioned $N_{\text {СтM }}-\rho_{\mathrm{t}}$ relationships; the $\rho_{t}-Z_{\mathrm{et}}$

508 relationships are shown in Fig. $5 \mathrm{c}$ (pelitic schist: $Z_{\mathrm{et}}=1.45 \rho_{\mathrm{t}}+8.7, \gamma=0.827$; tonalite: $Z_{\mathrm{et}}=$

$\left.5092.78 \rho_{\mathrm{t}}+4.76, \gamma=0.802\right)$. The $Z_{\mathrm{ec}}$ values are consistent with the $Z_{\mathrm{et}}$ values and possess errors of $510<7.9 \%$ (Table 4).

\subsubsection{The Tsuruga Fault at the Oritodani outcrop}

514 The CT results for samples T-3, K1, and T-5 (Fig. 8a-c) are representative of the five samples

515 (T-3, C-2, K-1, C-1, and T-5) collected from the Oritodani outcrop.

516 Sample T-3, which was taken from the rocks in the fault fracture zone that formed during the

517 most recent fault activity, appears dark in the fault gouge (T-3-1, T-3-2 and T-3-3) around the

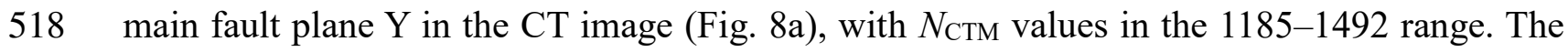

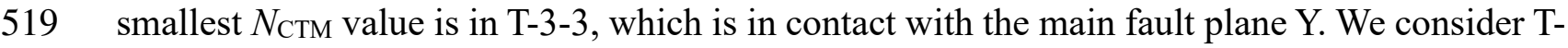

$520 \quad 3-2$ to be possibly affected by the most recent fault activity based on our abovementioned

521 analysis, but its $N_{\text {СтM }}$ value is 1428 , which is about the same as that in T-3-1 and exceeds that

522 in AT-2, a fault gouge along an inactive fault. Furthermore, the observed microstructures in T-

5233 suggest that repetitive fault activity, which is indicative of an active fault, is limited to fault 
524 gouge T-3-3. Therefore, we classify T-3-1 and T-3-2 as inactive fault gouge, and T-3-3 as active

525 fault gouge in this analysis. The cataclasite (T-3-4) outside of the fault gouge appears brighter

526 than the fault gouge, with a $N_{\text {СTM value of } 1622 .}$

527 Sample K-1, a Koujaku granite protolith, possesses dark-gray and fine-grained white areas

528 throughout the CT images (Fig. 8b), with a $N_{\text {CTM }}$ value of 1656 . The small white areas $(\leq 2-\mathrm{mm}$

529 diameter) in the image are inferred to be biotite, which has a larger effective atomic number

530 than either quartz or plagioclase.

531 Sample T-5, which is a metabasalt protolith, is largely gray in the CT image, with the exception

532 of a white area at the upper right of the sample (Fig. 8c) and has a $N_{\text {CTM value of } 2590 .}$

533 Example CT value histograms for each zone are shown in Fig. 8d-h. Approximately 20,000-

534310,000 pixels are analyzed in each region, with the $N_{\text {Стм values generally following a normal }}$

535 distribution and possessing a standard deviation of 70-206 (Table 4). There may be a slight

536 increase in the frequency to values above $N_{\text {CTM }}$ due to the influence of minerals with a large

537 effective atomic number in some instances, but $N_{\text {СTM }}$ corresponds to the CT value of the matrix,

538 with the influence of these minerals excluded.

539 Figure $8 \mathrm{i}-\mathrm{k}$ shows the CT value distributions along the white dash-dotted lines in the CT images

540 We note that the $N_{\text {CTMedian }}$ values (T-3: 1204-1553, K-1: 1706, ATS-2: 2612) are almost

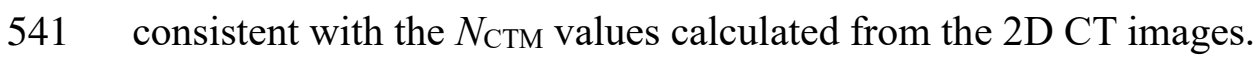


542 The $N_{\text {СтM }}-\rho_{\mathrm{t}}$ relationships for Koujaku granite and metabasalt have high positive correlations

543 (granite: $\rho_{\mathrm{t}}=1.23 \times 10^{-3} N_{\mathrm{CTM}}+0.45, \gamma=0.872$; metabasalt: $\rho_{\mathrm{t}}=5.47 \times 10^{-4} N_{\mathrm{CTM}}+1.42, \gamma=$

5440.967 ; Fig. 10d, e). The $\rho_{\mathrm{c}}$ values are the $\rho_{\mathrm{t}}$ values, and possess errors of $<3.7 \%$ (Table 4 ).

545 The $N_{\text {СтM }}-Z_{\text {et }}$ relationships (granite: $Z_{\text {et }}=2.83 \times 10^{-4} N_{\text {Стм }}+11.6$; metabasalt: $Z_{\text {et }}=7.66 \times 10^{-}$

$\left.546{ }^{4} N_{\mathrm{CTM}}+12.1\right)$ can be derived from the abovementioned $N_{\mathrm{CTM}}-\rho_{\mathrm{t}}$ relationships; the $\rho_{\mathrm{t}}-Z_{\mathrm{et}}$

547 relationships are shown in Fig. $5 \mathrm{c}$ (granite: $Z_{\mathrm{et}}=0.23 \rho_{\mathrm{t}}+11.5, \gamma=0.528$; metabasalt: $Z_{\mathrm{et}}=$

$\left.5481.40 \rho_{\mathrm{t}}+10.1, \gamma=0.669\right)$. The $Z_{\mathrm{ec}}$ values are consistent with the $Z_{\mathrm{et}}$ values and possess errors of $549<3.7 \%$ (Table 4).

\subsubsection{The Yamada Fault at the Mushu outcrop}

553 Sample YDA, which is from the Miyazu granite in the fault fracture zone at the Mushu outcrop,

554 appears dark in the fault gouge of the CT image (YDA-3; Fig. 9a), with a $N_{\text {CTM value of } 1108 .}$

555 The smallest $N_{\text {CTM }}$ value is in YDA-3, which is adjacent to the main fault plane Y. The

556 cataclasite zone (YDA-4), which is outside of the fault gouge, is brighter than the fault gouge,

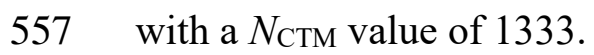

558 Sample YK-1, a Miyazu granite protolith, possesses dark-gray and fine-grained white areas

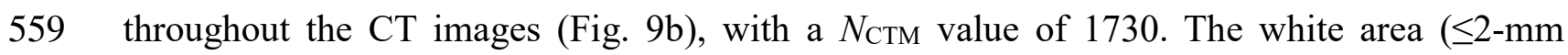


560 diameter) in the image is inferred to be biotite, which has a larger effective atomic number than

561 both quartz and plagioclase.

562 Example CT value histograms for each zone are shown in Fig. 9c-e. Approximately 50,000-

563330,000 pixels were analyzed in each region, with the $N_{\text {CTM }}$ values generally following a normal

564 distribution and possessing a standard deviation of 119-224 (Table 4). There may be a slight

565 increase in the frequency to values above $N_{\text {CTM }}$ due to the influence of minerals with a large

566 effective atomic number in some instances; however, $N_{\mathrm{CTM}}$ corresponds to the CT value of the

567 matrix, with the influence of these minerals excluded.

568 Fig. 9f and g show the CT value distributions along the white dash-dotted lines in the CT image.

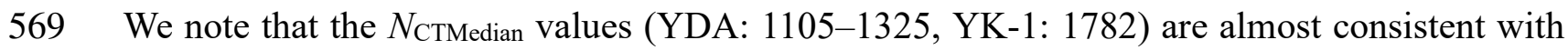

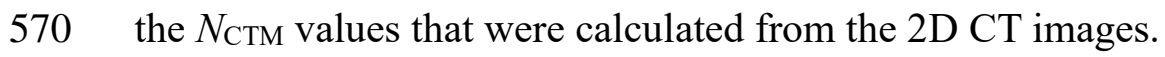

571 The $N_{\mathrm{CTM}}-\rho_{\mathrm{t}}$ relationship for Miyazu Granite has a high positive correlation $\left(\rho_{\mathrm{t}}=9.79 \times 10^{-4}\right.$

$572 N_{\mathrm{CTM}}+0.85, \gamma=0.893$; Fig. 10f). The $\rho_{\mathrm{c}}$ value is consistent with $\rho_{\mathrm{t}}$, and possesses an the error

573 of $<9.1 \%$ (Table 4$)$.

574 The $N_{\mathrm{CTM}}-Z_{\text {et }}$ relationship $\left(Z_{\text {et }}=6.95 \times 10^{-4} N_{\mathrm{CTM}}+11.2\right)$ can be derived from the

575 abovementioned $N_{\mathrm{CTM}}-\rho_{\mathrm{t}}$ relationship; the $\rho_{\mathrm{t}}-Z_{\mathrm{et}}$ relationship is shown in Fig. $5 \mathrm{c}\left(Z_{\mathrm{et}}=0.71 \rho_{\mathrm{t}}+\right.$

$57610.6, \gamma=0.975$ ). The $Z_{\mathrm{ec}}$ value is consistent with $Z_{\mathrm{et}}$, and possesses an error of $<0.7 \%$ (Table 4 ). 


\section{Discussion}

580 We have concluded that $N_{\text {СтM }}$ can be used to estimate $\rho_{\mathrm{t}}$ and $Z_{\text {et }}$ for the protolith and fault rock

581 samples. Here we further investigate the $\rho_{\mathrm{t}}-\rho_{\mathrm{c}}$ and $Z_{\mathrm{et}}-Z_{\mathrm{ec}}$ relationships, in addition to the fault

582 rock characteristics based on the $N_{\mathrm{CTM}}-$ rock/protolith ratio $\left(\rho_{\mathrm{t}}\right.$ and $\left.Z_{\mathrm{et}}\right)$ relationship to validate

583 the feasibility of employing CT-based methods to characterize fault zones.

584

$585 \quad 5.1 \rho_{t}-\rho_{c}$ and $Z_{\text {et }}-Z_{\text {ec }}$ relationships

586 There is no significant difference in the $\rho-\phi$ relationship for various fault rock and protolith

587 types (Fig. $5 \mathrm{~b}$ ), whereas the trend of the $\rho_{\mathrm{t}}-Z_{\mathrm{et}}$ relationship appears to be dependent on the 588 analyzed fault rock/protolith type (Fig. 5c). This indicates that $N_{\mathrm{CTM}}$, which is a function of $\rho$ 589 and $Z_{\mathrm{e}}$, must be treated as an effective parameter for examining fault rock and protolith 590 characteristics by fault rock/protolith type. We observe strong correlations between $\rho_{\mathrm{c}}$ and $\rho_{\mathrm{t}}$,

591 and $Z_{\mathrm{ec}}$ and $Z_{\mathrm{et}}$ for each fault rock and protolith type, as shown in Fig. $11\left(\rho: \gamma=0.944, Z_{\mathrm{e}}: \gamma=\right.$

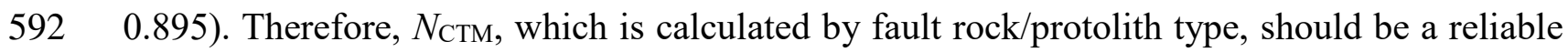
593 parameter for calculating the $\rho_{\mathrm{t}}$ and $Z_{\mathrm{et}}$ values of a given rock sample and determining its fault 594 rock/protolith characteristics. 


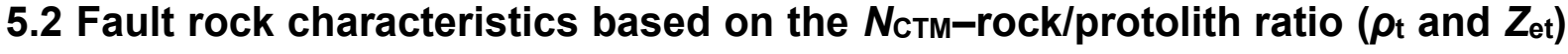
relationship

599 We have demonstrated that $\rho_{\mathrm{t}}, Z_{\mathrm{et}}$, and $N_{\text {CTM }}$ all decrease as the main fault plane is approached

600 Furthermore, $\rho_{\mathrm{t}}$ is affected by $Z_{\mathrm{et}}$, as shown in Fig. 5c, with a distinct $\rho_{\mathrm{t}}-Z_{\mathrm{et}}$ relationship for each

601 fault and protolith type. Therefore, the effect of $Z_{\text {et }}$ on $\rho_{\mathrm{t}}$ is suppressed by using the $602 \mathrm{rock} /$ protolith density ratio of each fault and protolith type.

603 Table 5 shows the results of the analyzed fault rock characteristics based on the relationships

604 between $N_{\text {СTM }}$ and the $\rho_{\mathrm{t}}$ and $Z_{\text {et }}$ rock/protolith ratios. The statistics of the determined $N_{\text {CTM }}$ 605 values and the $\rho_{\mathrm{t}}$ and $Z_{\text {et }}$ rock/protolith ratios are provided in Table 6 and Fig. 12a-c.

606

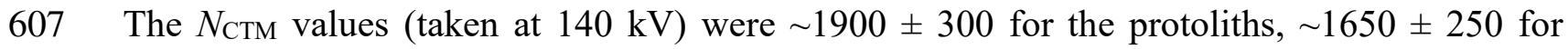
608 cataclasite, $\sim 1450 \pm 200$ for the fault gouge along inactive faults, and $\sim 1100 \pm 100$ for the fault 609 gouge along active faults, as shown in Fig. 12a. Both the $N_{\text {CTM }}$ values and $N_{\text {CTM variations }}$ 610 decrease as the fault rock becomes more heavily deformed and the main fault plane is 611 approached.

612 The rock/protolith $\rho_{\mathrm{t}}$ ratio was $\sim 0.8 \pm 0.15$ for cataclasite and the fault gouge along inactive

613 faults, and $\sim 0.7 \pm 0.1$ for the fault gouge along active faults, as shown in Fig. $12 \mathrm{~b}$. The $\rho_{\mathrm{t}}$ ratio 
614 decreases as the fault rock becomes more heavily deformed and the main fault plane is

615 approached, whereas the variation in the $\rho_{\mathrm{t}}$ ratio is approximately constant. Furthermore, the $\rho_{\mathrm{t}}$

616 ratio differences among the different rock types are smaller than the $N_{\text {CTM }}$ differences.

617 The rock/protolith $Z_{\text {et }}$ ratio was $\sim 0.85$, with no major difference between the analyzed fault rock

618 types, as shown in Fig. 12c. Therefore, $Z_{\text {et }}$ is not closely related to the fault rock types, which

619 indicates that any distinct characteristics are dependent on differences in the protolith type (Fig.

$6205 c)$

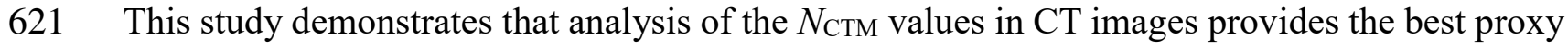

622 for detecting changes in fault rocks characteristics as the youngest active domain of a fault zone

623 is approached. Furthermore, the $\rho_{\mathrm{t}}$ ratio of the active fault is smaller than those of other fault

624 rocks, and the $Z_{\text {et }}$ ratio decreases by $\sim 15 \%$, regardless of the protolith type. This occurs because

$625 N_{\text {CTM }}$, which is a function of both $\rho$ and $Z_{\mathrm{e}}$, is affected by both the changes in $\rho$ (dependent on

626 the fault rock type) and decreases in $Z_{\mathrm{e}}$. This is also due to how $N_{\mathrm{CTM}}$ and the rock/protolith

627 ratios are calculated: $N_{\text {CTM }}$ is calculated from more than 12,000 pixels of data by eliminating

628 the sample area due to the influence of cracks or minerals with a large effective atomic number,

629 with the rock/protolith $\rho_{\mathrm{t}}$ and $Z_{\text {et }}$ ratios also calculated using only a portion of each sample area.

630 The $N_{\mathrm{CTM}}-$ rock/protolith $\rho_{\mathrm{t}}$ ratio relationship is shown in Fig. $12 \mathrm{~d}$. Both $N_{\mathrm{CTM}}$ and the

631 rock/protolith $\rho_{\mathrm{t}}$ ratio decrease as the main fault plane is approached and/or the degree of 
632 fracturing increases. However, there is significant overlap between the $N_{\mathrm{CTM}}-\rho_{\mathrm{t}}$ ratio

633 distribution areas for the fault gouge along the inactive fault and cataclasite, making it difficult

634 to classify them using $N_{\text {СтM }}$ and the $\rho_{\mathrm{t}}$ ratio. However, there is no overlap between the $N_{\text {СTM }}$

635 values for the fault gouges along active and inactive faults. Therefore, there is a possibility that

636 both fault rocks can be classified when $N_{\text {СТМ }} \approx 1200$ is set as the boundary, which remains a

637 future task in its application to the classification of active faults and inactive faults.

638 The youngest active domain of a fault zone can be recognized as the area with the smallest

$639 N_{\text {CTM }}$ and rock/protolith $\rho_{\mathrm{t}}$ ratio. It is expected that the accuracy of the $\rho_{\mathrm{t}}$ and $Z_{\text {et }}$ values obtained

640 from the CT values in the fault fracture zone will be further enhanced as more studies conduct

641 CT analyses on both active and inactive faults, and a greater diversity of protoliths.

642

\section{Conclusions}

644 This study considered fault rock and protolith samples that were derived from pelitic schist,

645 tonalite, metabasalt, and granite along active faults (MTL, and Tsuruga and Yamada faults) and

646 an inactive fault (MTL). The density, porosity, and effective atomic number were determined

647 for the different fault and protolith types, and relationships among the CT value, density, and

648 effective atomic number were investigated. Our major findings and conclusions are as follows.

649 (1) The fault rock density, $\rho_{\mathrm{t}}$, decreases as it approaches the youngest active fault plane, and the 
650 porosity, $\phi$, tends to increase by $\sim 24 \%$ as $\rho_{\mathrm{t}}$ decreases by $1 \mathrm{~g} / \mathrm{cm}^{3}$, regardless of the fault rock

651 or protolith type.

652 (2) The mean $\phi$ values are $1.5 \%(\mathrm{SD}=1.0 \%)$ for the protoliths, $12.6 \%(\mathrm{SD}=6.9 \%)$ for 653 cataclasite, $12.0 \%(\mathrm{SD}=4.8 \%)$ for the fault gouge along the inactive fault, $17.4 \%(\mathrm{SD}=4.6 \%)$

654 for the fault gouge along the active faults, and $32.2 \%$ for the fault breccia.

655 (3) There is a positive correlation between $\rho_{\mathrm{t}}$ and the effective atomic number, $Z_{\mathrm{et}}$, which is 656 unique to each fault and protolith type.

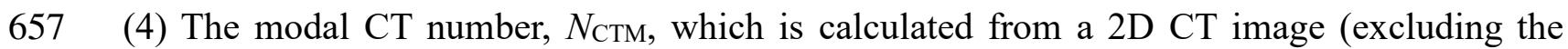
658 periphery where $\mathrm{BH}$ is significant, and the influences of cracks and minerals with a large 659 effective atomic number) can be used to estimate the $\rho_{\mathrm{t}}$ and $Z_{\text {et }}$ values of the protolith and fault 660 rock samples.

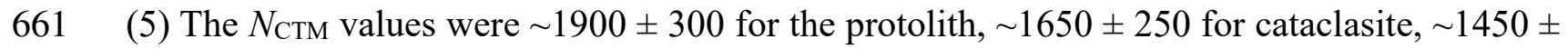
662200 for fault gouge in the inactive fault, and $\sim 1100 \pm 100$ for fault gouge in the active faults.

663 Both $N_{\text {СтM }}$ and the variation in $N_{\text {СTM }}$ decreased near the main fault plane. There is a possibility 664 that both fault rocks can be classified with $N_{\mathrm{CTM}} \approx 1200$ as the boundary, which remains a future 665 task in its application to the classification for active and inactive faults.

666 (6) The rock/protolith density ratio was $\sim 0.8 \pm 0.15$ for cataclasite and fault gouge along the 667 inactive fault, and $\sim 0.7 \pm 0.1$ for fault gouge along the active faults. 
668 (7) The change in fault rock characteristics due to the transition to the youngest active domain

669 of the fault zone is more distinct when analyzing $N_{\mathrm{CTM}}$, which is a function of the $\rho_{\mathrm{t}}$ and $Z_{\mathrm{et}}$,

670 than the rock/protolith $\left(\rho_{\mathrm{t}}\right.$ and $\left.Z_{\mathrm{et}}\right)$ ratios.

671 (8) The youngest active domain of a fault zone can be recognized as the fault rock area with the

672 smallest $N_{\mathrm{CTM}}$ and rock/protolith $\rho_{\mathrm{t}}$ ratio.

673

674

\section{Declarations}

676 Availability of data and material

677 Data sharing not applicable to this article as no datasets were generated now. Please contact

678 author for data requests.

679

680 Competing interests

681 The authors of this article declare that they have no competing interest.

682

683 Funding

684 This work was funded by Kansai Electric Power Co. Inc..

685 
687 AI proposed this study and performed compilation and interpretation on all analysis results. HT 688 provided support and guidance for all analyzes and interpretation of analysis results. NA 689 captured CT images and performed XRF analysis. TS took the lead in sampling of fault rocks.

690 EN, SN and KU collaborated with the corresponding author to interpret analysis results. All 691 authors read and approved the final manuscript.

692

\section{Acknowledgements}

694 We thank Seiji Matayoshi and Yasuhiro Yamada for their assistance with the analyses at CRIEPI.

695 We are grateful to Tadahiro Nishizaki for his assistance during the sample collection in the field.

696 Kana Tanabe, Shotaro Yamamoto, Kozo Kiyose, Koichi Hojo, and Koudai Kuramoto provided

697 careful guidance during the X-ray effective energy measurements and CT imaging.

698

\section{References}

700 Aiyama K, Tanaka S, Sasaki T (2017) Consideration of the Activity of a Fault Based on Detailed

701 Structural Analysis of a Fault Fracture Zone: Case Study of the Yamada Fault, Western Japan.

702 J. Japan Soc. Eng. Geol., 58. 1, 2-18.*

703 Boespflug X, Long BFN, Occhietti S (1995) CAT-scan in marine stratigraphy: a quantitative 
704 approach. Marine Geol. 122, 281-301.

705 Earthquake Research Committee (2004) Long-term evaluation of the Yamada Fault Zone. The

706 Headquarters for

for Earthquake Research Promotion.

707 https://www.jishin.go.jp/main/chousa/katsudansou_pdf/74_yamada.pdf/*

708 Geet MV, Swennen R, Wevers M (2000) Quantitative analysis of reservoir rocks by microfocus

709 X-ray computerized tomography. Sedimentary Geol., 132, 25-36

710 Hirono T, Sakaguchi M, Otsuki K, Sone H, Fujimoto K, Mishima T, Lin W, Tanikawa W,

711 Tanimizu M, Soh W, Yeh E, Song S (2008) Characterization of slip zone with the 1999 Taiwan

712 Chi-Chi earthquake: X-ray CT image analyses and microstructural observation of the Taiwan

713 Chelungpu fault. Tectonophysics. 449, 63-84.*

714 Hounsfield GN (1973) Computerized transverse axial scanning (tomography): Part I .

715 Description of system. British J. Radiology, 46, 1016-1022.

716 Hubbell JH (1982) Photon mass attenuation and energy-absorption coefficients from $1 \mathrm{keV}$ to

$71720 \mathrm{MeV}$. Int. J. Appl. Radiat. Isot. 33, 1269-1290.

718 Ikeda R, Omura K, Iio Y, Arai T, Kobayashi K, Matsuda T, Shimada K, Tanaka H, Tomita T,

719 Hirano S (2001) Drilling investigation through the Nojima Fault of the 1995 Hyogo-ken Nanbu

720 Earthquake, Japan. National Research Institute for Earth Science and Disaster Prevention

721 Research Report, 61, 141-153.* 
723 (2015) Activity history of the Yamada fault in the late Quaternary -Outcrop survey at Mushu,

724 Tanto-cho. Proceedings of the 2015 Autumn Meeting of the Active Fault Society of Japan, 62-

$72563 .^{*}$

726 Iwamori A, Takagi H, Asahi N, Sugimori T, Nakata E, Nohara S, Ueta K (2020) Development

727 of a method for presuming the density and effective atomic number of mineral samples by

728 utilizing medical X-ray CT scanning. Jap. Mag. Mineral. Petrol. Sci., 49, 101-117. *

729 Ketchman RA, Carlson WD (2001) Acquisition, optimization and interpretation of X-ray

730 computed tomographic imagery: applications to the geosciences. Comp. Geosci. 27, 381-400.

731 Ketchman RA, Hanna RD (2014) Beam hardening correction for X-ray computed tomography

732 of heterogeneous natural materials. Comp. Geosci. 67, 49-61.

733 Kurimoto C, Naito K, Sugiyama Y, Nakae S (1999) Geological map of Japan 1:50,000, Tsuruga,

734 National Institute of Advanced Industrial Science and Technology.*

735 Mizoguchi K, Ueta K (2012) Evaluation of fault activity based on fault-zone properties -

736 Microfracture analysis of damage zone along an active fault located east of epicentral area of

737 the 1943 Tottori Earthquake, Japan -. Civil Engin. Res. Lab. Rep. No. N11041, 17 pp.*

738 Morrow CA, Lockner DA (2001) Hayward fault rocks: Porosity, density and strength

739 measurements. U.S. Department of the Interior, USGS Open-File Report 2001-421 
740 Nakano T, Nakashima Y, Nakamura K, Ikeda S (2000) Observation and analysis of internal

741 structure of rock using X-ray CT. J. Geol. Soc. Japan 106, 363-378.*

742 National Institute of Advanced Industrial Science and Technology (2016) 151 Tsuruga

743 earthquake fault. Active fault database of Japan. https://gbank.gsj.jp/activefault/*

744 Nishioka Y, Nakae S, Takeuchi K, Banno Y, Mizuno K, Ozaki M, Nakashima R, Sanematsu K,

745 Nawa K, Komazawa M (2010) Geological map of Japan 1:200,000, Ise, National Institute of

746 Advanced Industrial Science and Technology.*

747 Nishizawa O, Nakano T, Noro H, Inazaki T (1995) Recent advances of X-ray CT technology

748 for analyzing geologic materials. Bull. Geol. Surv. Japan 46, 565-571.*

749 Okada A (1992) Proposal of the segmentation on the Median Tectonic Line active fault system.

750 Mem. Geol. Soc. Japan. 40, 15-30.*

751 Orsi TH, Edwards CM, Anderson AL (1994) X-ray computed tomography: A nondestructive

752 method for quantitative analysis of sediment cores. J. Sed. Res, A64, 690-693.

753 Raynaud S, Fabre D, Mezerolle F, Geraud Y, Latiere HJ (1989) Analysis of the internal structure

754 of rocks and characterization of mechanical deformation by a non-destructive method: X-ray

755 tomodensitometry. Tectonophysics. 159, 149-159

756 Shigematsu N, Kametaka M, Inada N, Miyawaki M, Miyakawa A, Kameda J, Togo T, Fujimoto

757 K (2017) Evolution of the Median Tectonic Line fault zone, SW Japan, during exhumation. 
Tectonophysics. 696-697, 52-69.

759 Takagi H (1984) Mylonitic rocks along the Median Tectonic Line in Takato-Ichinose area,

760 Nagano Prefecture. J. Geol. Soc. Japan. 90, 81-100.*

761 Takagi H (1985) Mylonitic rocks of the Ryoke belt in the Kayumi area, eastern part of the Kii

762 Peninsula. J. Geol. Soc. Japan. 91, 637-651.*

763 Takagi H, Kobayashi K (1996) Composite planar fabrics of fault gouges and mylonites-

764 comparative petrofabrics. J. Geol. Soc. Japan 102, 170-179.*

765 Takagi H, Sugiyama K, Tamura I, Mizuno K, Kitazawa N, Kawamoto K (2019) Identification

766 of the youngest activity of the Median Tectonic Line at Hiji outcrop, Ina City, Nagano

767 Prefecture. Active Fault Res. 50, 1-12.*

768 Takeuchi F, Nakamura K, Matsumura K, Watanabe K (2005) Density of stones observed near

769 and around the Yamazaki Fault System. Annuals of Disas. Prev. Res. Inst., Kyoto Univ., 48B.*

770 Tanaka Y, Kametaka M, Okazaki K, Suzuki K, Seshimo K, Aoki K, Shimada K, Watanabe T,

771 Nakayama K (2018) Examination of Evaluation Method for Fault Activity Based on

772 Morphological Observation of Fault Planes. J. Japan Soc. Eng. Geol., 59. 1, 13-27.*

773 The Japanese Geotechnical Society (2017) Japanese Geotechnical Society Standards Vol. 2-

774 Laboratory Testing Standards of Geomaterials, 300p.*

775 Tsuchiyama A, Uesugi K, Nakano T (2000) A Study of three-dimensional structures of rocks 
776 and minerals using a high-resolution X-ray CT method - primitive materials in the solar system

777 and chondrules. J. Geogr. (Chigaku Zasshi) 109, 845-858.*

778 Ueta K, Tani K, Kato T (2000) Computerized X-ray tomography analysis of three-dimensional

779 fault geometries in basement-induced wrench faulting. J. Eng. Geol. 56, 197-210.

780 Verhelst F, David P, Fermont W, Jegers L, Vervoort A (1996) Correlation of 3D-computerized

781 tomographic scans and 2D-colour image analysis of Westphalian coal by means of multivariate

782 statistics. Int. J. Coal Geol. 29, 1-21.

783 Wellington SL, Vinegar HJ (1987) X-ray computerized tomography. J. Petrol. Tech. 39, 885784898.

785

$786 *$ in Japanese with English abstract.

787

788

\section{Figure legends}

790 Figure 1. Simplified geotectonic map showing the location of the study area around the MTL

791 and the Tsuruga and Yamada faults. The stars denote the approximate locations where the

792 samples were collected; see Fig. 2 for further details on each sample site. 
794 Figure 2. Geological maps of the area around (a) the MTL in the Ina area, (b) the MTL in the

795 Matsusaka area, (c) the Tsuruga Fault, and (d) the Yamada Fault. These maps have been

796 simplified and partly modified after the 1/200,000 geological maps from the National Institute

797 of Advanced Industrial Science and Technology (AIST): (a) Kofu (2002), (b) Ise (2010), (c)

798 Gihu (1992), and (d) Miyazu (1968). The stars denote the approximate locations of fault

799 outcrops and where the samples were collected.

800

801 Figure 3. Photographs of the outcrop (a, e), and polished slab (b, f) of the observed brittle fault

802 rocks taken perpendicular to the fault plane and parallel to the lineations, and photomicrographs

803 (c, d, g, h; cross-polarized light) of the fault rock samples. (a) The Hiji outcrop of the MTL. (b)

804 HJ8. (c) HJ8-1. (d) HJ8-3. (e) The Awano-Tabiki outcrop of the MTL. (f) AT. (g) AT-1-AT-2-

805 AT-4. (h) AT-2-AT-4. The stereoplots show the orientation of fault plane Y and the direction of

806 slip in the zone formed during the most recent fault movements (a, e). Abbreviations in (g) and

807 (h): P: P-foliation; $\mathrm{R}_{1}$ : Riedel shear; Pn, Pr: P foliations showing normal and reverse senses of

808 shear, respectively; $\mathrm{R}_{1} \mathrm{n}, \mathrm{R}_{1} \mathrm{r}$ : Riedel shear showing normal and reverse senses of shear,

809 respectively.

810

811 Figure 4. Outcrop photographs (a, f), observed brittle fault rocks in the outcrops, photographs 
812 taken perpendicular to the fault plane and parallel to the lineations $(\mathrm{b}, \mathrm{g})$, and photomicrographs

813 of the fault rock and protolith samples (c, d, e, h, i: cross-polarized light). (a) The Oritodani

814 outcrop of the Tsuruga Fault. (b) T-3. (c) T-3-2-T-3-3. (d) T-3-2. (e) T-3-3. (f) The Mushu

815 outcrop of the Yamada Fault. (g) YDA. (h) YDA-4. (i) YDA-2-YDA-3. Stereoplots show the

816 orientation of fault plane $\mathrm{Y}$ and slip direction in the zone formed during the most recent fault

817 movements (a, f). Abbreviations: P: P-foliation; R 1 : Riedel shear.

818

819 Figure 5. Density, porosity, and effective atomic number measurement results. (a) Relationship

820 between fault rock type and real density, $\rho_{\mathrm{t}}$ (b) Crossplot of porosity, $\phi$, versus $\rho_{\mathrm{t}}$. (c) Crossplot

821 of effect atomic number, $Z_{\mathrm{et}}$, versus $\rho_{\mathrm{t}}$.

822

823 Figure 6. X-ray CT image analysis results for the Hiji outcrop samples. CT images of samples

824 (a) HJ-8 and (b) MZ-5. CT number histograms for (c) HJ8-1, (d) HJ8-3, and (e) MZ-5. The

825 modal CT number, $N_{\mathrm{CTM}}$, for each zone was calculated near the center (within the white dotted

826 line), with the peripheral CT numbers excluded. CT number profiles for (f) HJ-8 and (g) MZ-

827 5, with the values calculated along the dash-dotted lines in (a) and (b), respectively.

828

829 Figure 7. X-ray CT image analysis results for the Awano-Tabiki outcrop samples. CT images 

2, (f) AT-4, (g) HA-1, and (h) ATS-2 samples. The $N_{\text {CTM }}$ value for each zone was calculated near the center (within the white dotted lines in (a)-(c)), with the peripheral areas excluded. CT number profiles for (i) AT, (j) HA-1, and (k) ATS-2, with the values calculated along the dash-

834 dotted lines in (a)-(c), respectively.

836 Figure 8. X-ray CT image analysis results for the Oritodani outcrop samples. CT images of samples (a) T-3, (b) K-1, and (c) T-5. CT number histograms for (d) T-3-1, (e) T-3-3, (f) T-3-4, white dotted lines in (a)-(c)), with the peripheral values excluded. CT number profiles for (i)

841 respectively.

843 Figure 9. X-ray CT image analysis results for the Mushu outcrop samples. CT images of the (a)

844 YDA and (b) YK-1 samples. CT number histograms for (c) YDA-3, (d) YDA-4, and (e) YK-1.

845 The $N_{\text {Стм }}$ values were calculated near the center (within the white dotted lines in (a) and (b))

846 of each zone, with the peripheral areas excluded. CT number profiles for (f) YDA and (g) YK-

847 1, with the values calculated along the dash-dotted lines in (a) and (b), respectively. 
849 Figure 10. $\rho_{\leftarrow}-N_{\mathrm{CTM}}$ crossplots for the sampled fault rocks and protoliths. (a) Schist (Hiji 850 outcrop). (b) Schist (Awano-Tabiki outcrop). (c) Tonalite (Awano-Tabiki outcrop). (d) Granite

851 (Oritodani outcrop). (e) Metabasalt (Oritodani outcrop). (f) Granite (Mushu outcrop).

853 Figure 11. Crossplots of (a) the real density, $\rho_{\mathrm{t}}$, versus the measured density, $\rho_{\mathrm{c}}$, which is 854 calculated from $N_{\mathrm{CTM}}$, and (b) the real effective atomic number, $Z_{\text {et }}$, versus the measured 855 effective atomic number, $Z_{\mathrm{ec}}$, which is calculated from $N_{\text {Стм. }}$ Regression lines were determined 856 via least-squares analysis.

857

858 Figure 12. Box plots of (a) $N_{\mathrm{CTM}}$, (b) rock/protolith $\rho_{\mathrm{t}}$ ratio, (c) and rock/protolith $Z_{\mathrm{et}}{ }^{3.8}$ ratio, 859 and (d) crossplot of $N_{\mathrm{CTM}}$ versus rock/protolith $\rho_{\mathrm{t}}$ ratio.

860

861 Tables

862 Table 1. Locations and fault/protolith details of the analyzed samples. See Figs 1 and 2 for 863 sample locations.

864

865 Table 2. Density, porosity, and XRF analysis results. 
867 Table 3. XRF analysis and effective atomic number $\left(Z_{\mathrm{et}}\right)$ results for the rock samples.

868

869 Table 4 . Relationship among $N_{\mathrm{CTM}}$ (calculated from the CT images at $140 \mathrm{kV}$ ), $\rho_{\mathrm{t}}$, and $Z_{\mathrm{et}}$ for

870 each of the samples.

871

872 Table 5. Comparison of $\rho_{\mathrm{t}}, Z_{\mathrm{et}}, N_{\mathrm{CTM}}$, and the rock/protolith ratios $\left(\rho_{\mathrm{t}}\right.$ and $\left.Z_{\mathrm{et}}{ }^{3.8}\right)$ for each of the

873 analyzed samples.

874

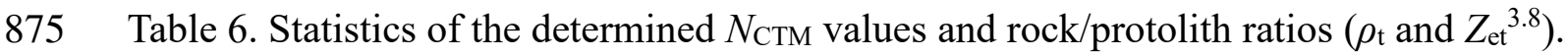

876 


\section{Figures}

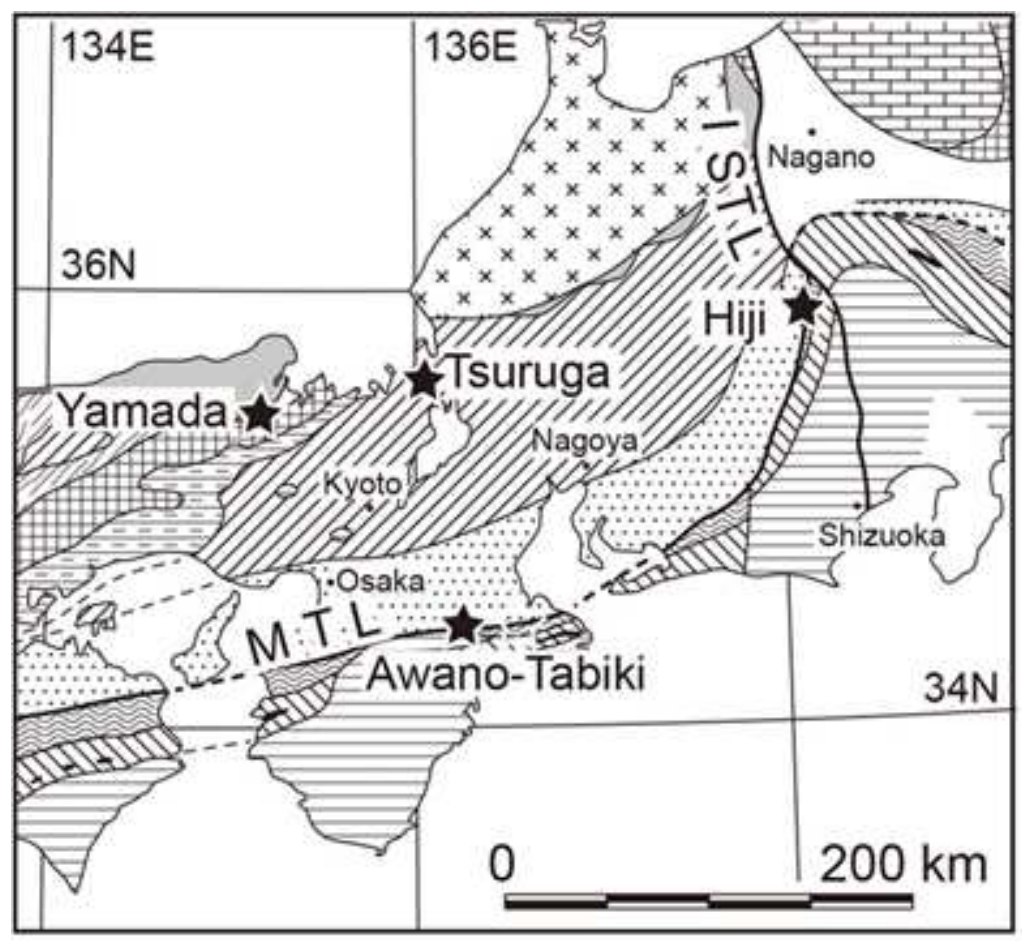

$\left.x_{x}^{x} \times\right]$ Hida-Oki Belt Hida-gaien Belt Akiyoshi Belt Suo-Chizu Belt

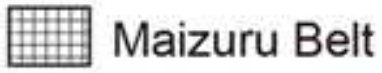
圈 Ultra-Tanba Belt

Mino-Tanba Belt Ryoke met. Belt Sanbagawa met. Belt $\mathbb{N}$ Chichibu Belt - Kurosegawa Terrane Shimanto Belt

MTL : Median Tectonic Line

ISTL: Itoigawa-Shiziuoka Tectonic Line met. : metamorphic

Figure 1

Simplified geotectonic map showing the location of the study area around the MTL and the Tsuruga and Yamada faults. The stars denote the approximate locations where the samples were collected; see Fig. 2 for further details on each sample site. Note: The designations employed and the presentation of the material on this map do not imply the expression of any opinion whatsoever on the part of Research Square concerning the legal status of any country, territory, city or area or of its authorities, or concerning the delimitation of its frontiers or boundaries. This map has been provided by the authors. 


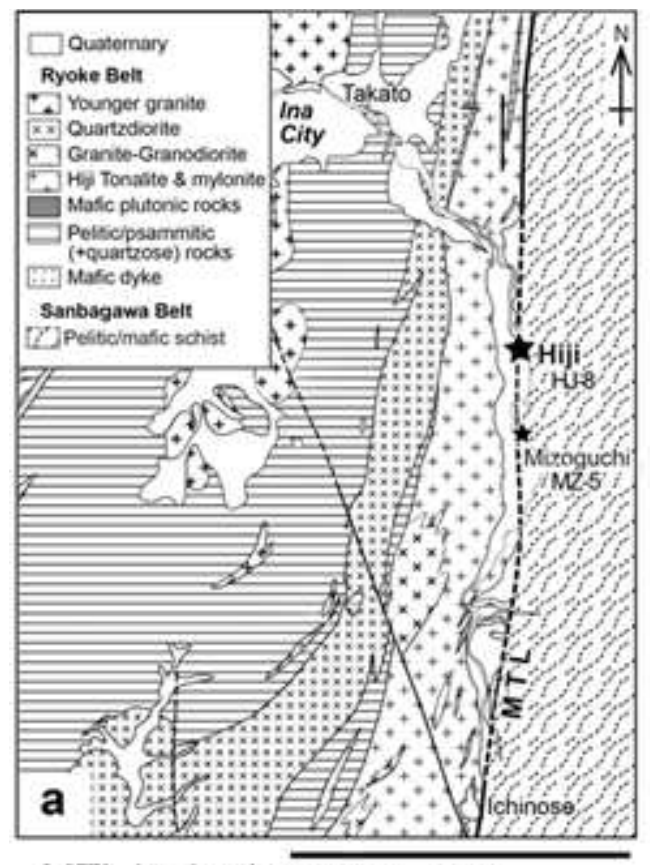

MTL in the Ina area $5 \mathrm{~km}$

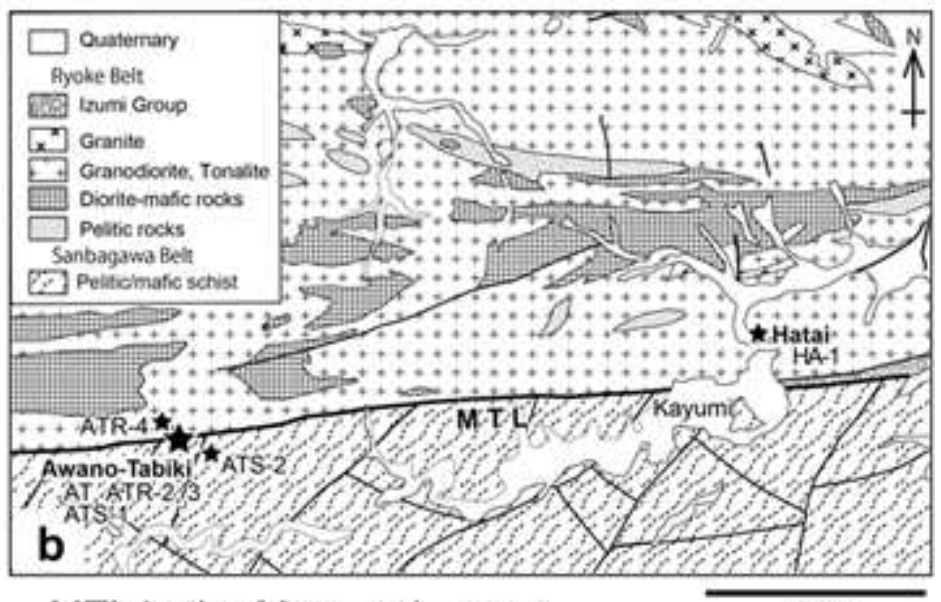

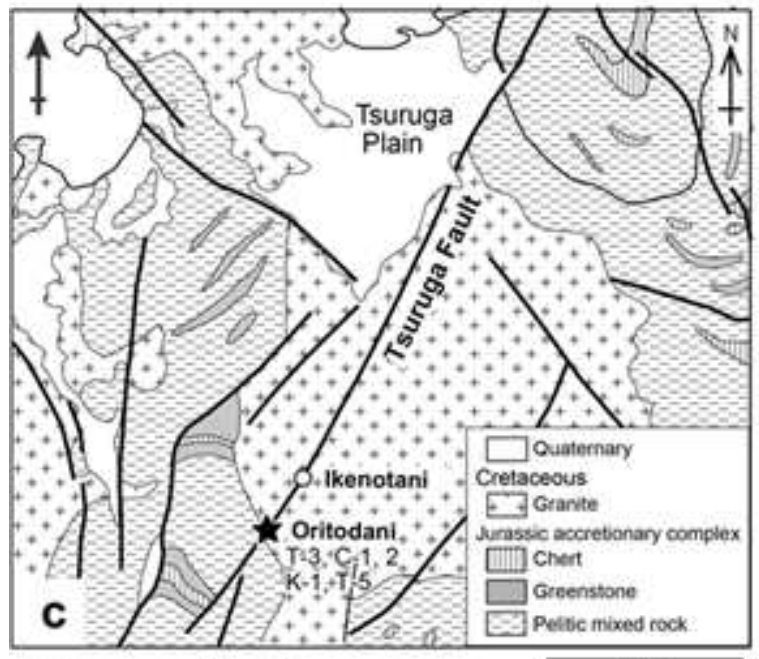

Tsuruga Fault

$5 \mathrm{~km}$

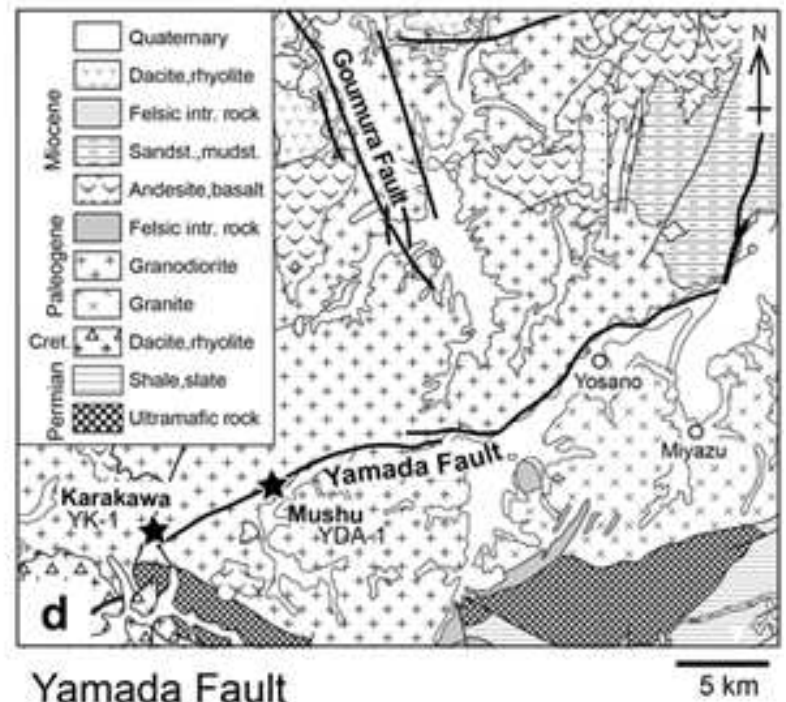

Figure 2

Geological maps of the area around (a) the MTL in the Ina area, (b) the MTL in the Matsusaka area, (c) the Tsuruga Fault, and (d) the Yamada Fault. These maps have been simplified and partly modified after the 1/200,000 geological maps from the National Institute of Advanced Industrial Science and Technology (AIST): (a) Kofu (2002), (b) Ise (2010), (c) Gihu (1992), and (d) Miyazu (1968). The stars denote the approximate locations of fault outcrops and where the samples were collected. Note: The designations employed and the presentation of the material on this map do not imply the expression of any opinion whatsoever on the part of Research Square concerning the legal status of any country, territory, city or area or of its authorities, or concerning the delimitation of its frontiers or boundaries. This map has been provided by the authors. 

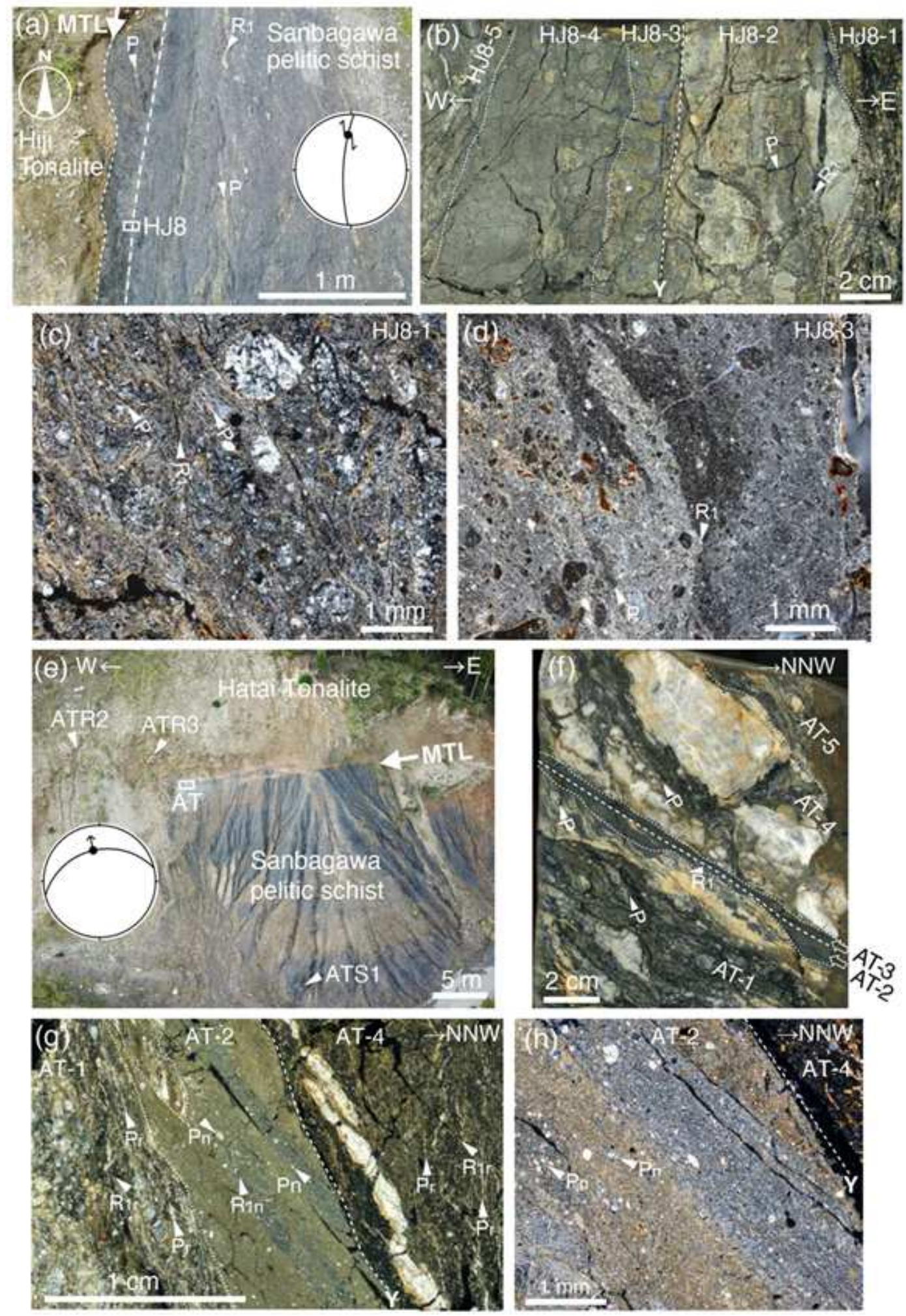

\section{Figure 3}

Photographs of the outcrop $(a, e)$, and polished slab $(b, f)$ of the observed brittle fault rocks taken perpendicular to the fault plane and parallel to the lineations, and photomicrographs (c, d, g, h; crosspolarized light) of the fault rock samples. (a) The Hiji outcrop of the MTL. (b) HJ8. (c) HJ8-1. (d) HJ8-3. (e) The Awano-Tabiki outcrop of the MTL. (f) AT. (g) AT-1-AT-2-AT-4. (h) AT-2-AT-4. The stereoplots show the orientation of fault plane $\mathrm{Y}$ and the direction of slip in the zone formed during the most recent 
fault movements (a, e). Abbreviations in (g) and (h): P: P-foliation; R1: Riedel shear; Pn, Pr: P foliations showing normal and reverse senses of shear, respectively; R1n, R1r: Riedel shear showing normal and reverse senses of shear, respectively. Note: The designations employed and the presentation of the material on this map do not imply the expression of any opinion whatsoever on the part of Research Square concerning the legal status of any country, territory, city or area or of its authorities, or concerning the delimitation of its frontiers or boundaries. This map has been provided by the authors.
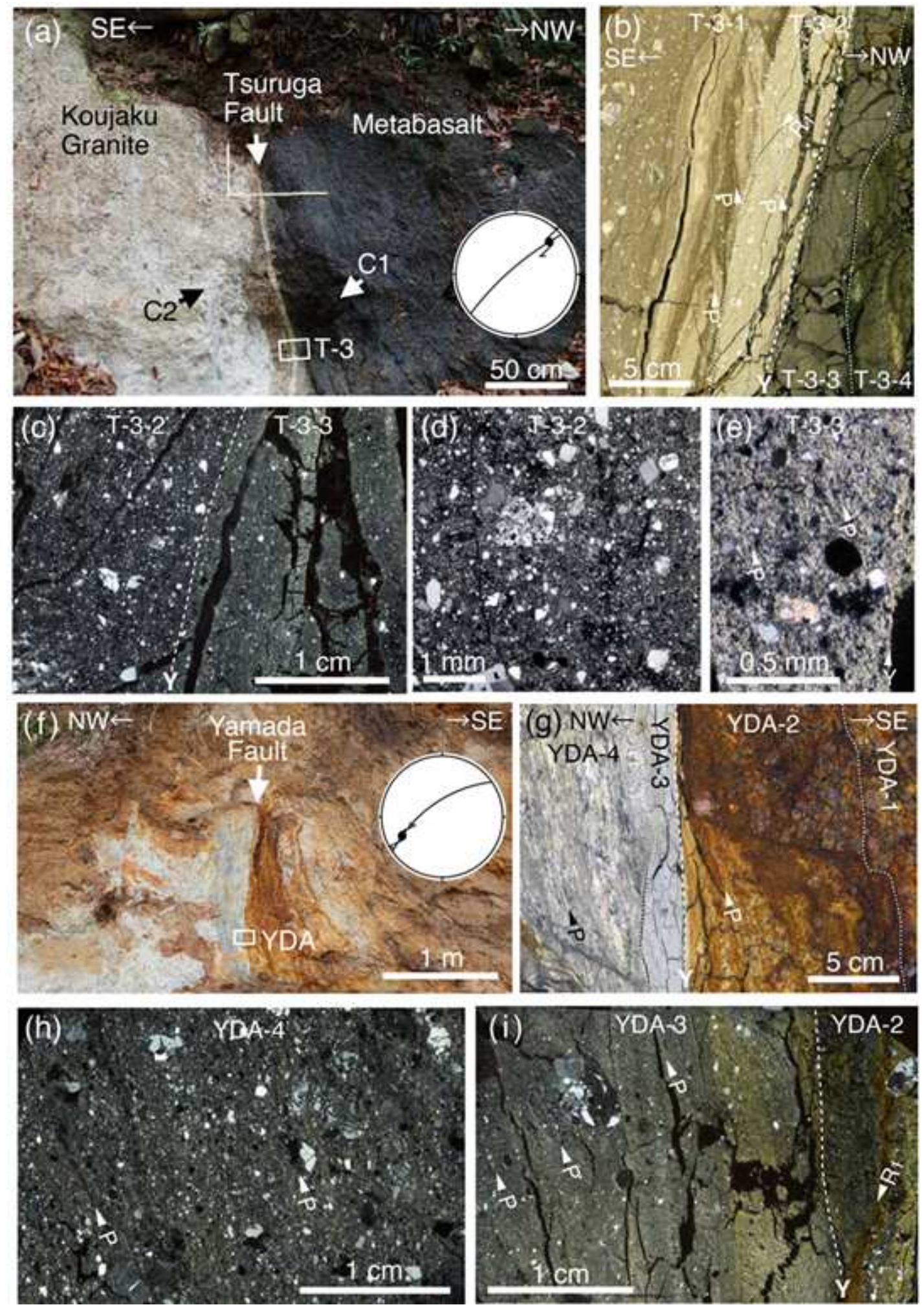

Figure 4 
Outcrop photographs $(\mathrm{a}, \mathrm{f})$, observed brittle fault rocks in the outcrops, photographs taken perpendicular to the fault plane and parallel to the lineations $(b, g)$, and photomicrographs of the fault rock and protolith samples (c, d, e, h, i: cross-polarized light). (a) The Oritodani outcrop of the Tsuruga Fault. (b) T-3. (c) T-32-T-3-3. (d) T-3-2. (e) T-3-3. (f) The Mushu outcrop of the Yamada Fault. (g) YDA. (h) YDA-4. (i) YDA-2YDA-3. Stereoplots show the orientation of fault plane $Y$ and slip direction in the zone formed during the most recent fault movements ( $a, f)$. Abbreviations: P: P-foliation; R1: Riedel shear. Note: The designations employed and the presentation of the material on this map do not imply the expression of any opinion whatsoever on the part of Research Square concerning the legal status of any country, territory, city or area or of its authorities, or concerning the delimitation of its frontiers or boundaries. This map has been provided by the authors.

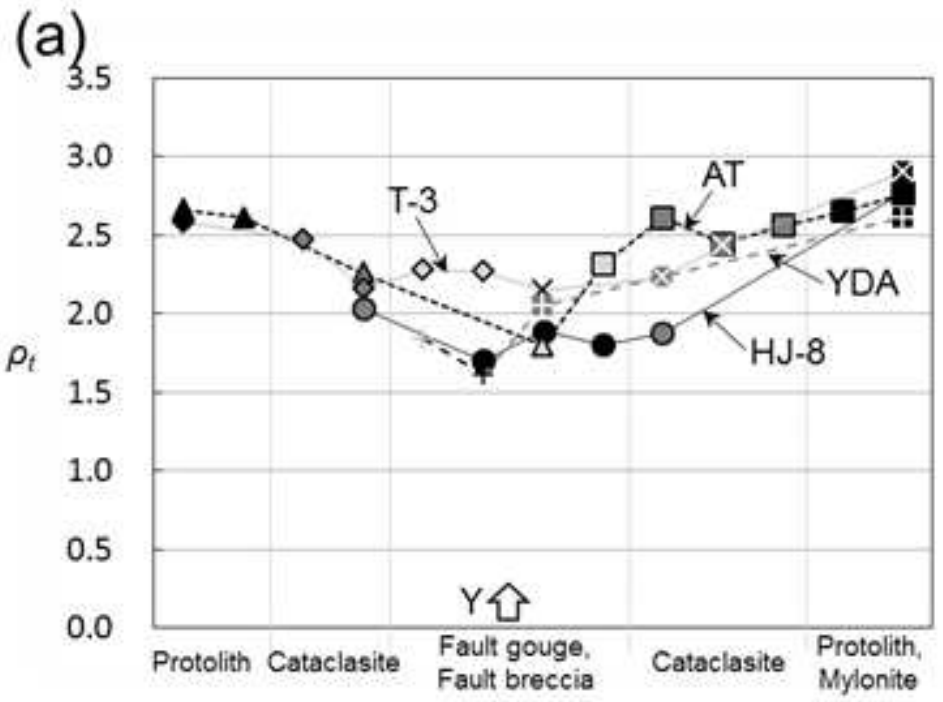

schist (MTL, Hiji) O fault gouge (active) 0 cataclasite - protolith schist (MTL, Awano-Tabiki) $\Delta$ fault gouge (inactive) $\Delta$ cataclasite $\Delta$ protolith tonalite (MTL, Awano-Tabiki) $\square$ fault gouge (inactive) $\square$ cataclasite - protolith, mylonite granite (Tsuruga, Oritodani) $\diamond$ fault gouge (inactive) $\diamond$ cataclasite - protolith

metabasalt (Tsuruga, Oritodani) $\times$ fault gouge (active) \& cataclasite protolith granite (Yamada, Mushu) fault breccia + fault gouge (active)

(b)

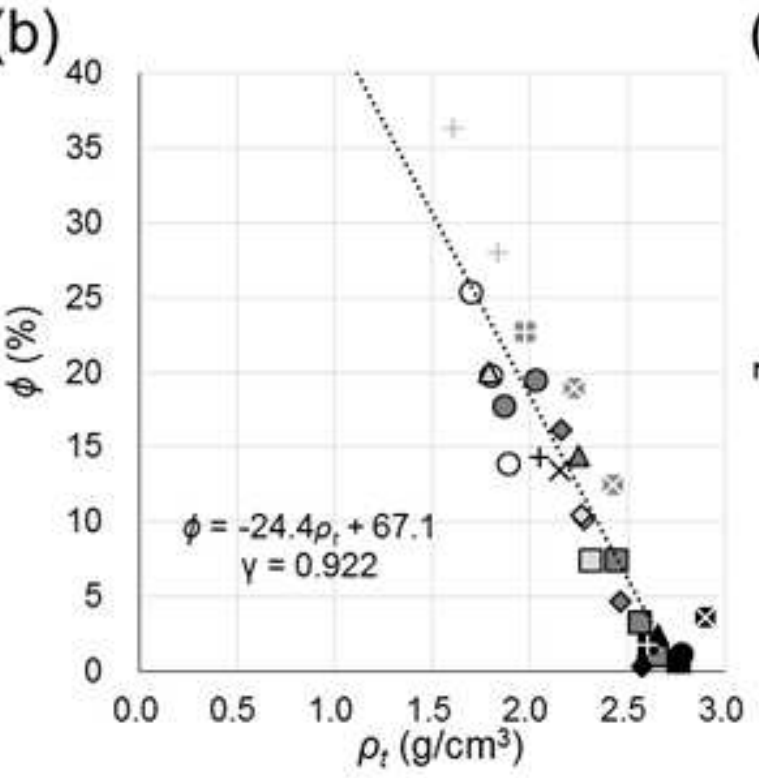

(c) \#cataclasite $\mathbf{m}$ protolith

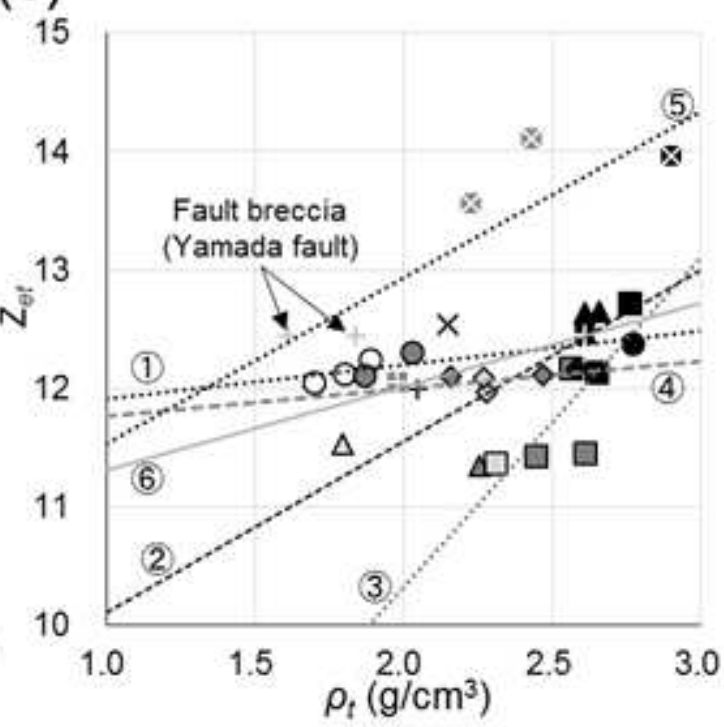

(1) Hiji : $Z_{e t}=0.28 \rho_{t}+11.6(\gamma=0.847)$. (2) Awanotabiki : $Z_{e t}=1.45 \rho_{t}+8.7(\gamma=0.827)$,

(3) Hatai : $Z_{e t}=2.78 \rho_{t}+4.76(y=0.802)$. (4) Koujaku : $Z_{e t}=0.23 \rho_{t}+11.5(y=0.528)$,

(5) Metabasalt : $Z_{e t}=1.40 \rho_{t}+10.1(\gamma=0.669)$, (6) Miyazu : $Z_{e t}=0.71 \rho_{t}+10.6(\gamma=0.975)$, 
Density, porosity, and effective atomic number measurement results. (a) Relationship between fault rock

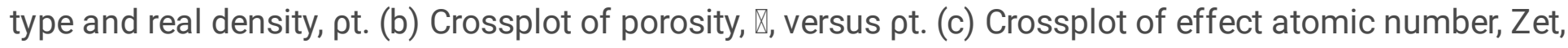
versus $p$ t.

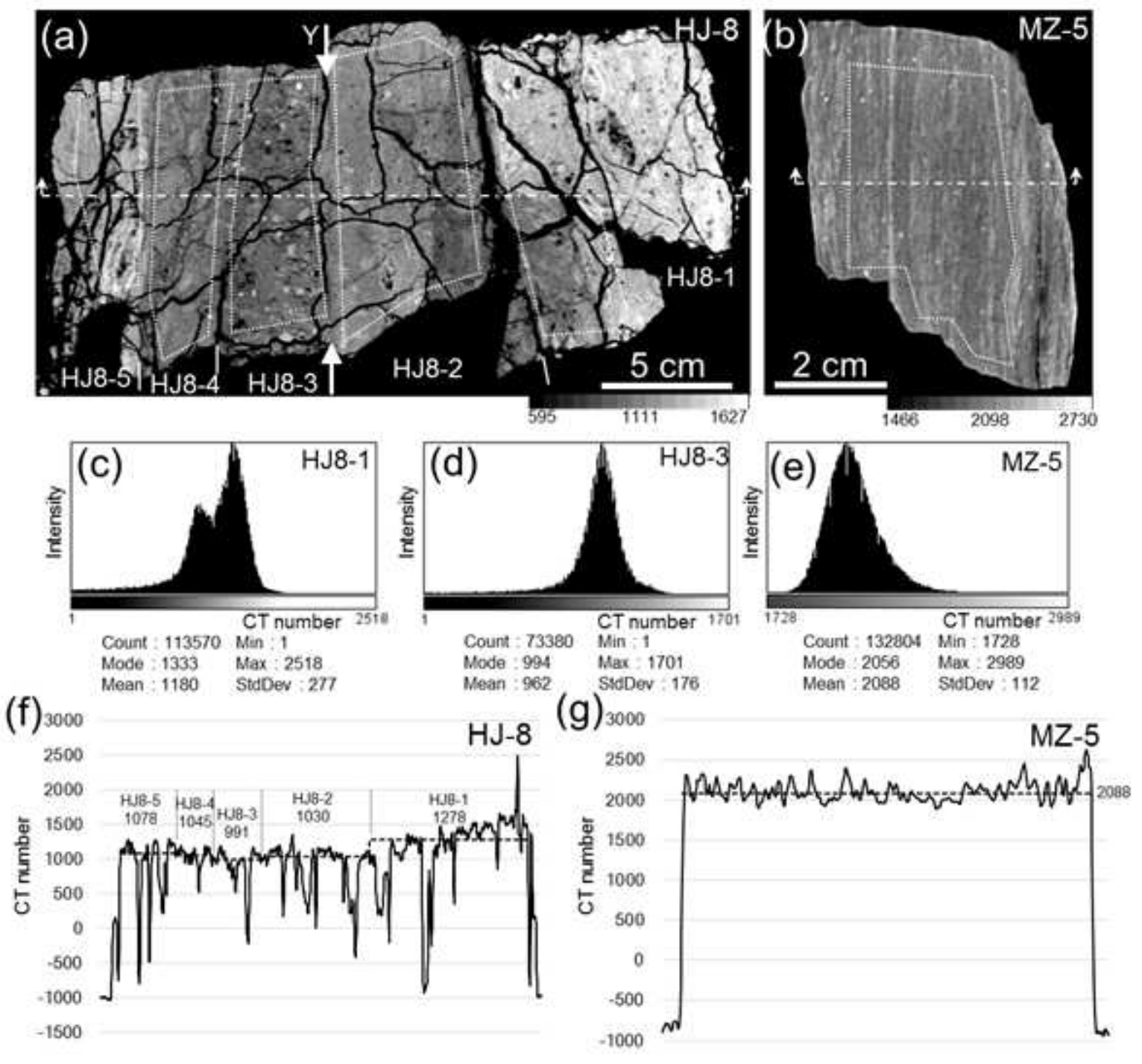

Figure 6

X-ray CT image analysis results for the Hiji outcrop samples. CT images of samples (a) HJ-8 and (b) MZ5. CT number histograms for (c) HJ8-1, (d) HJ8-3, and (e) MZ-5. The modal CT number, NCTM, for each zone was calculated near the center (within the white dotted line), with the peripheral CT numbers excluded. CT number profiles for (f) HJ-8 and (g) MZ-5, with the values calculated along the dash-dotted lines in (a) and (b), respectively. 

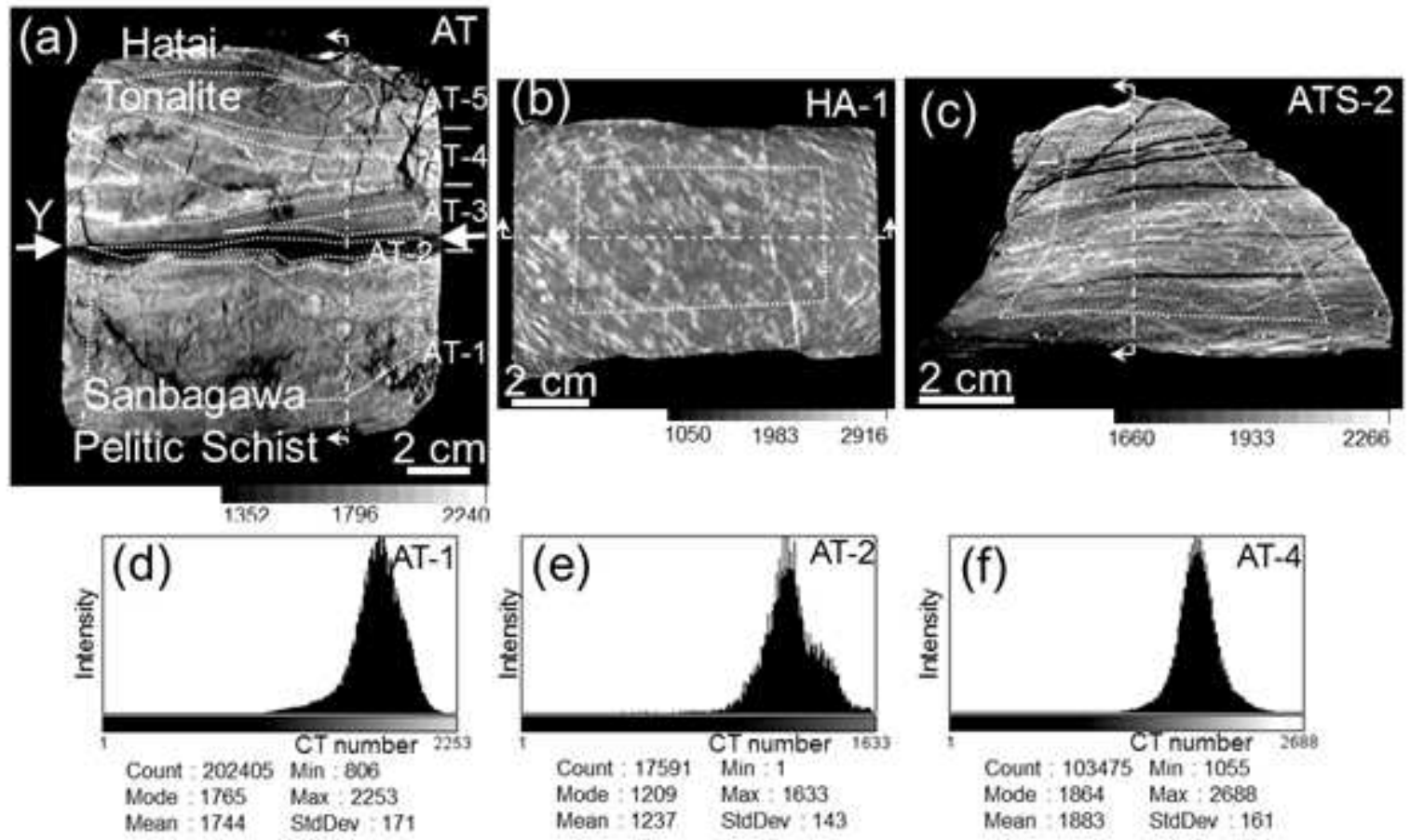

Count : 103475 Min : 1055

Mode : 1864 Max: 2688

Mean : $1893 \quad$ StdDev: 161
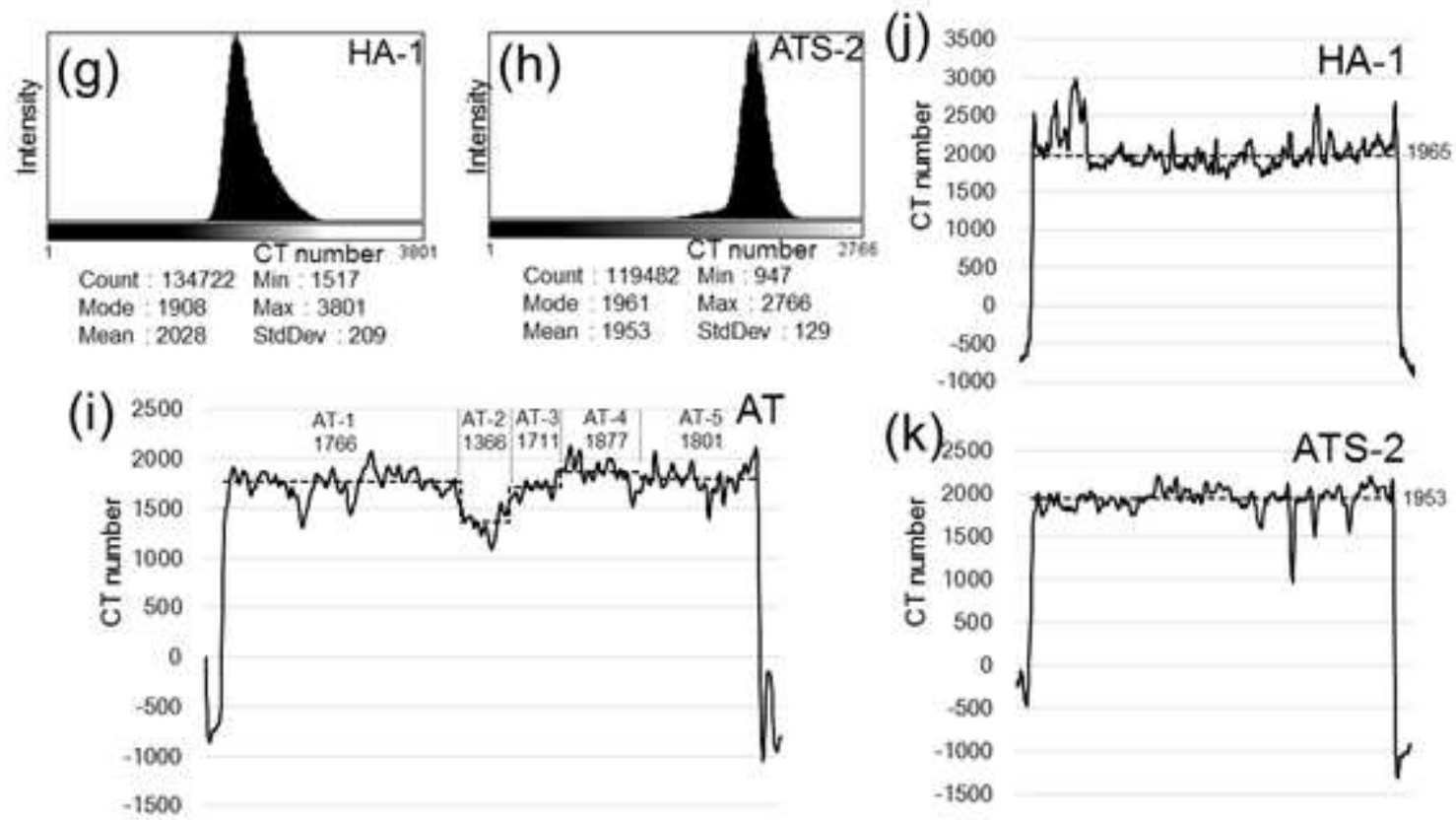

\section{Figure 7}

X-ray CT image analysis results for the Awano-Tabiki outcrop samples. CT images of the (a) AT, (b) HA1, and (c) ATS-2 samples. CT number histograms for the (d) AT-1, (e) AT-2, (f) AT-4, (g) HA-1, and (h) ATS-2 samples. The NCTM value for each zone was calculated near the center (within the white dotted lines in (a) - (c)), with the peripheral areas excluded. CT number profiles for (i) AT, (j) HA-1, and (k) ATS-2, with the values calculated along the dash-dotted lines in (a)-(c), respectively. 

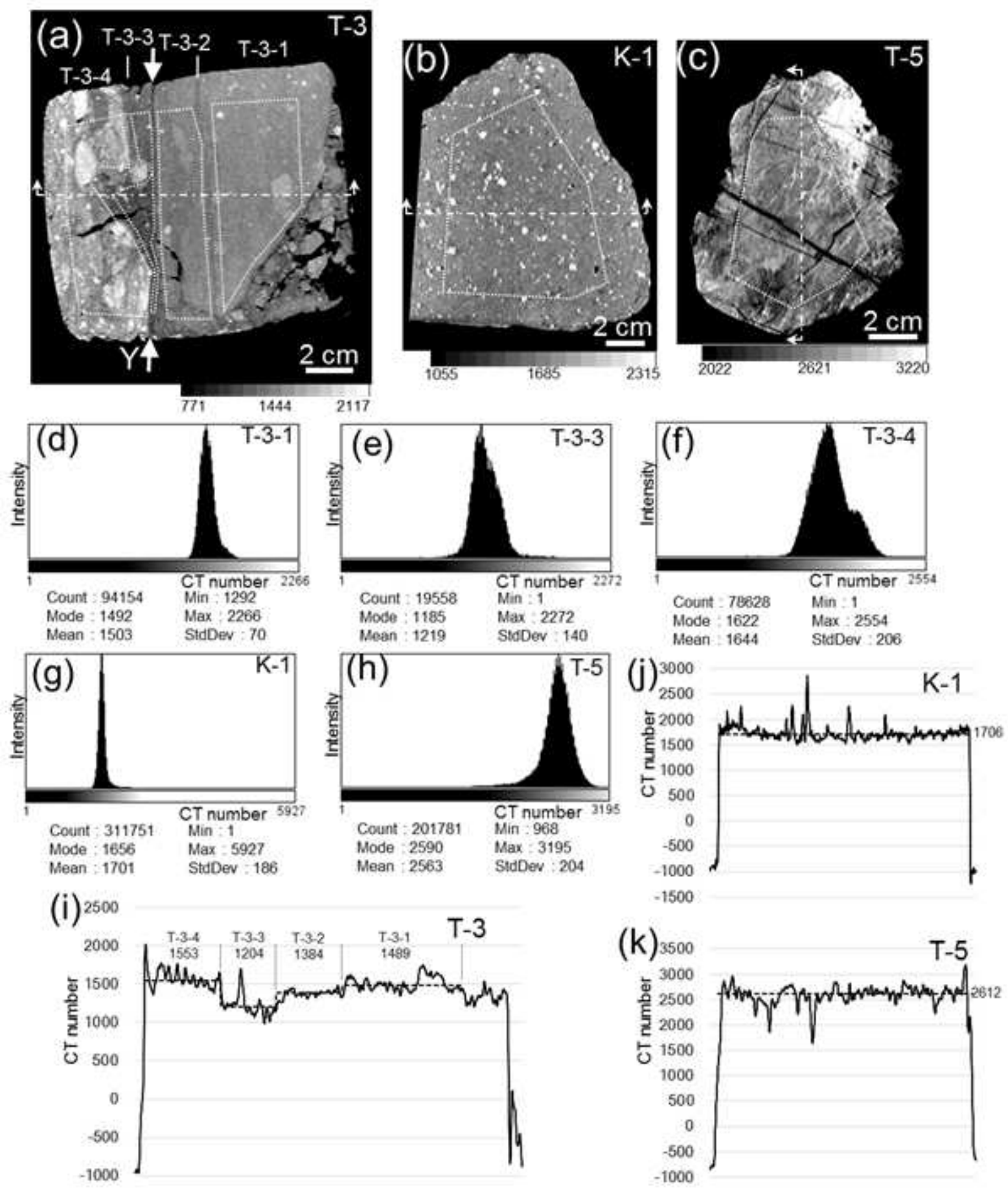

\section{Figure 8}

X-ray CT image analysis results for the Oritodani outcrop samples. CT images of samples (a) T-3, (b) K-1, and (c) T-5. CT number histograms for (d) T-3-1, (e) T-3-3, (f) T-3-4, (g) K-1, and (h) T-5. The NCTM value in each zone was calculated near the center (within the white dotted lines in (a)-(c)), with the peripheral values excluded. CT number profiles for (i) T-3, (j) K-1, and (k) T-5, with the values calculated along the dash-dotted lines in (a) $-(\mathrm{c})$, respectively. 

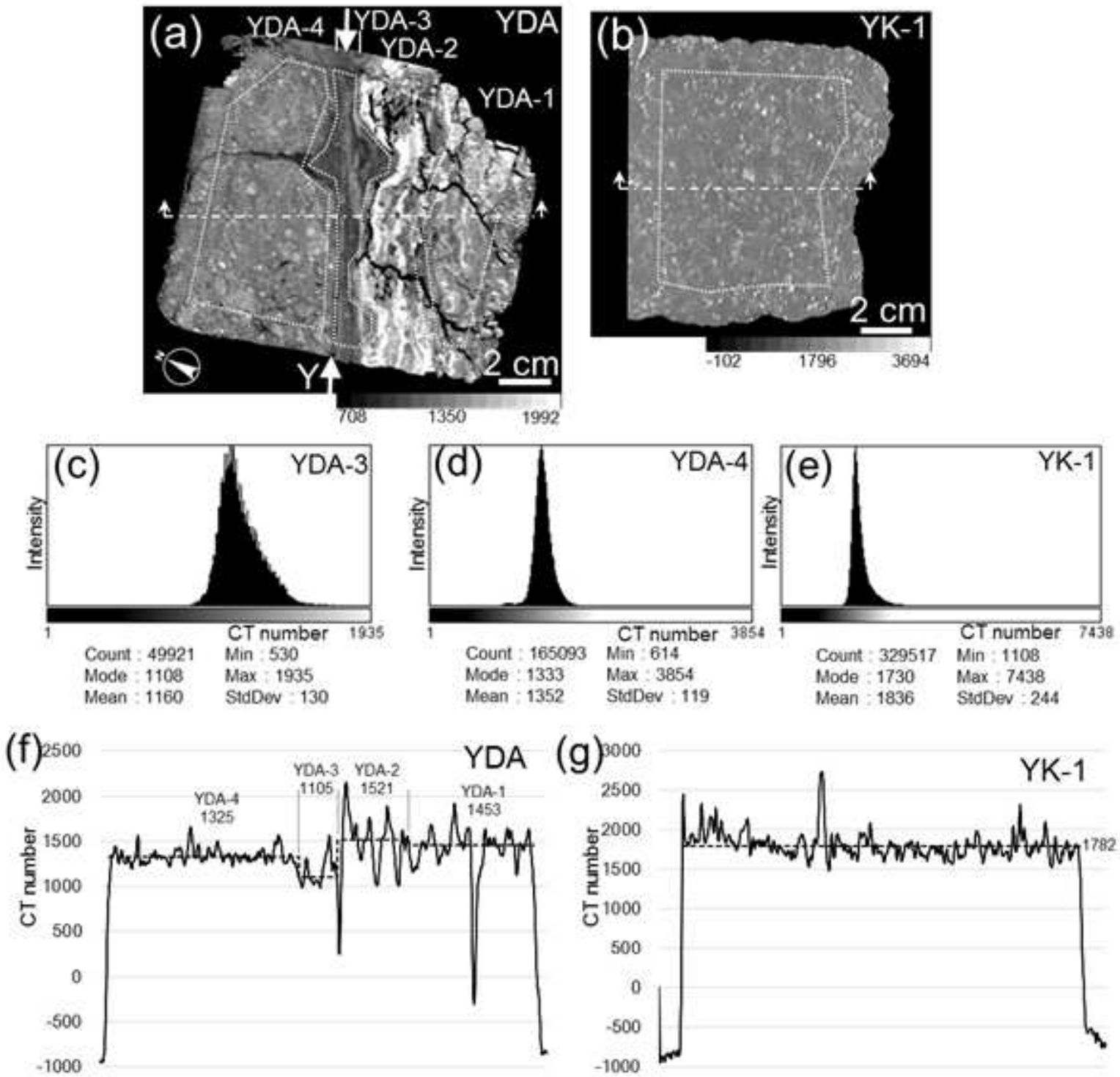

\section{Figure 9}

X-ray CT image analysis results for the Mushu outcrop samples. CT images of the (a) YDA and (b) YK-1 samples. CT number histograms for (c) YDA-3, (d) YDA-4, and (e) YK-1. The NCTM values were calculated near the center (within the white dotted lines in (a) and (b)) of each zone, with the peripheral areas excluded. CT number profiles for ( $f$ ) YDA and (g) YK-1, with the values calculated along the dash-dotted lines in (a) and (b), respectively. 

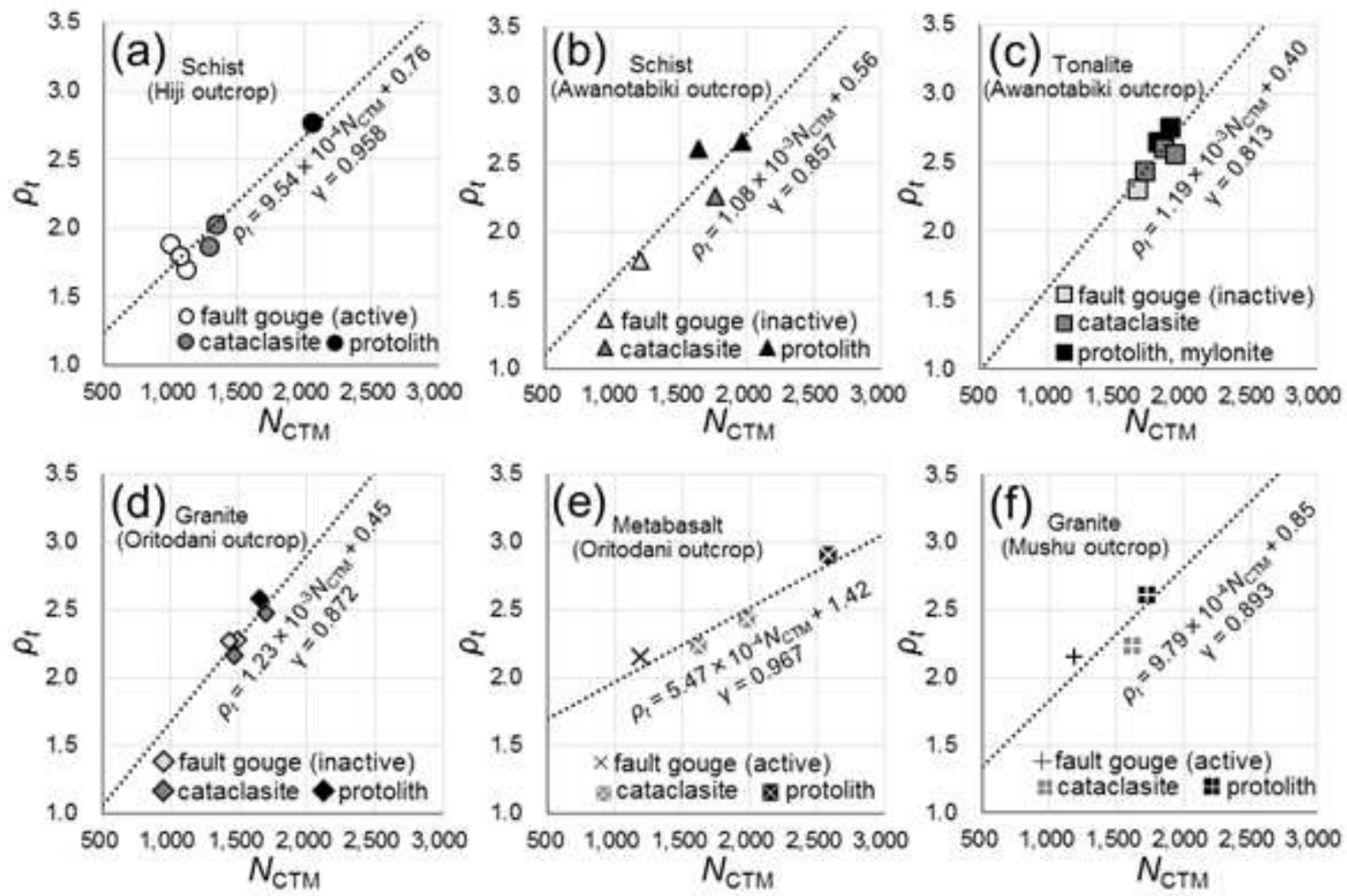

Figure 10

pt-NCTM crossplots for the sampled fault rocks and protoliths. (a) Schist (Hiji outcrop). (b) Schist (Awano-Tabiki outcrop). (c) Tonalite (Awano-Tabiki outcrop). (d) Granite (Oritodani outcrop). (e) Metabasalt (Oritodani outcrop). (f) Granite (Mushu outcrop).
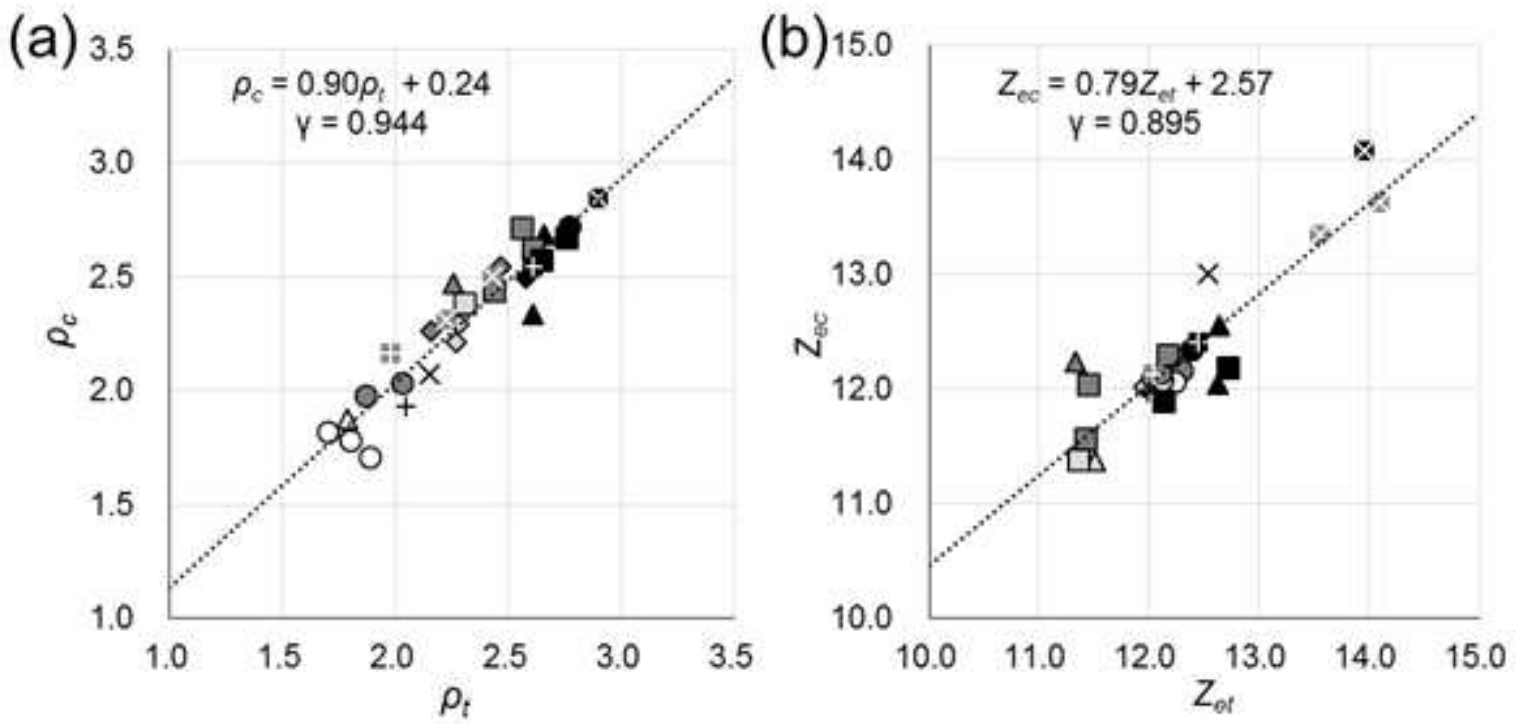

schist (MTL, Hiji) O fault gouge (active) O cataclasite protolith schist (MTL, Awano-Tabiki) $\Delta$ fault gouge (inactive) $\Delta$ cataclasite $\Delta$ protolith tonalite (MTL, Awano-Tabiki) $\square$ fault gouge (inactive) $\square$ cataclasite $\mathbf{E}$ protolith, mylonite granite (Tsuruga, Oritodani) $\diamond$ fault gouge (inactive) $\diamond$ cataclasite $\diamond$ protolith metabasalt (Tsuruga, Oritodani) $\times$ fault gouge (active) 5 cataclasite $\$$ protolith granite (Yamada, Mushu) fault breccia + fault gouge (active) acataclasite $\mathbf{a}$ protolith 
Crossplots of (a) the real density, pt, versus the measured density, $\rho c$, which is calculated from NCTM, and (b) the real effective atomic number, Zet, versus the measured effective atomic number, Zec, which is calculated from NCTM. Regression lines were determined via least-squares analysis.

(a)

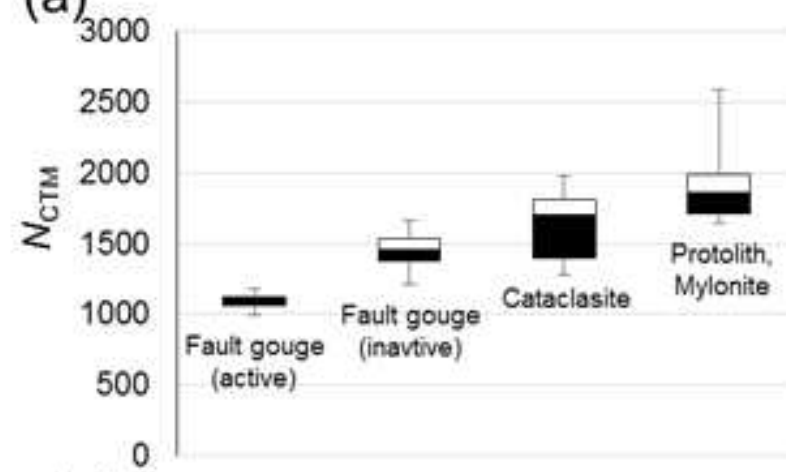

(c) 12

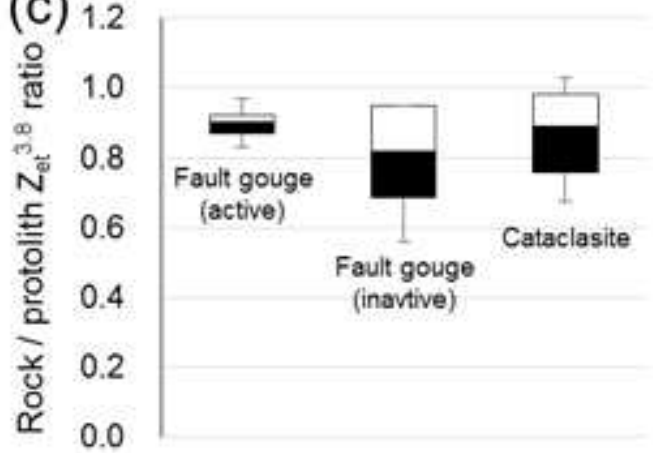

(b)

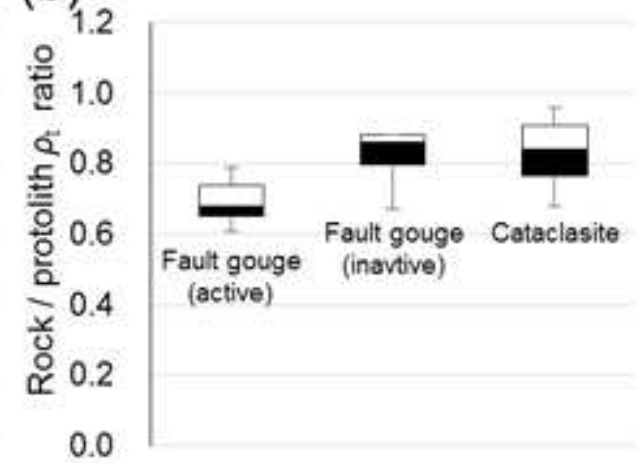

(d) 1.1
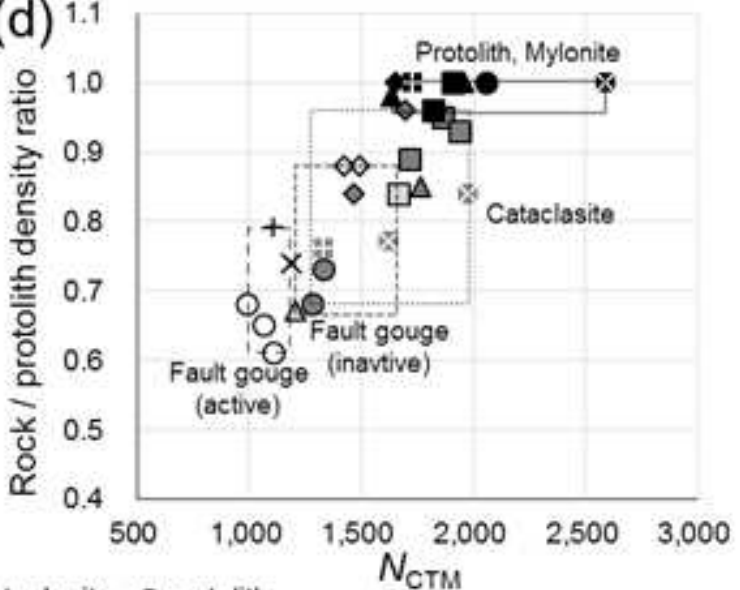

schist (MTL, Hiji) Ofault gouge (active) 0 cataclasite protolith schist (MTL, Awano-Tabiki) $\Delta$ fault gouge (inactive) $\Delta$ cataclasite $\mathbf{\Delta}$ protolith tonalite (MTL, Awano-Tabiki) $\square$ fault gouge (inactive) $\square$ cataclasite $\mathbf{m}$ protolith, mylonite granite (Tsuruga, Oritodani) $\diamond$ fault gouge (inactive) $\diamond$ cataclasite $\diamond$ protolith metabasalt (Tsuruga, Oritodani) $\times$ fault gouge (active) 8 cataclasite 8 protolith granite (Yamada, Mushu) fault breccia + fault gouge (active) \#ircataclasite $\mathbf{E}$ protolith

Figure 12

Box plots of (a) NCTM, (b) rock/protolith pt ratio, (c) and rock/protolith Zet3.8 ratio, and (d) crossplot of NCTM versus rock/protolith pt ratio.

\section{Supplementary Files}

This is a list of supplementary files associated with this preprint. Click to download.

- Iwamorietal2021Graphicalabstractimage.png

- Iwamorietal2021table1.docx

- Iwamorietal2021table2.docx

- Iwamorietal2021table3.docx 
- Iwamorietal2021table4.docx

- Iwamorietal2021table5.docx

- Iwamorietal2021table6.docx 